\title{
Hydraulic Laboratory Testing of SonTek-IO Plus
}
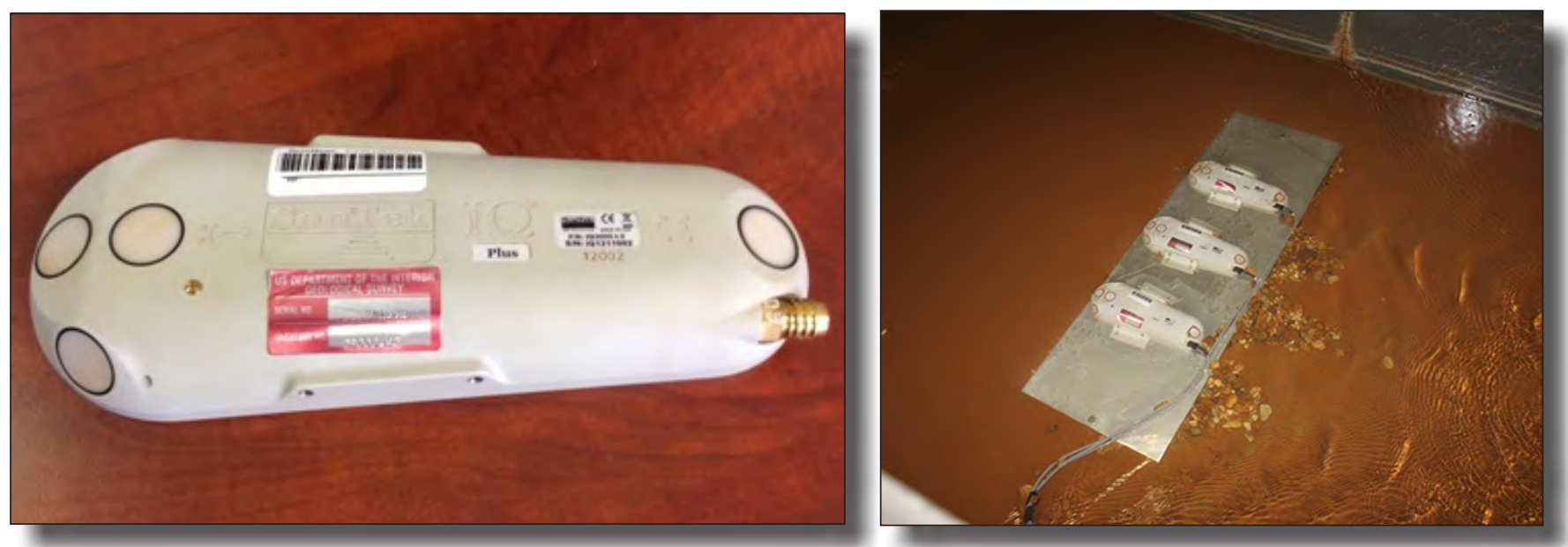

Open-File Report 2015-1139

U.S. Department of the Interior

U.S. Geological Survey 
Cover photographs. Left: SonTek-IQ Plus on office table without power and communication cable. Right: Three SonTek-IO Plus sensors mounted side by side on Hydraulic Laboratory tilting flume bottom. 


\section{Hydraulic Laboratory Testing of SonTek-IO Plus}

By Janice M. Fulford and Scott Kimball

Open-File Report 2015-1139

U.S. Department of the Interior

U.S. Geological Survey 


\title{
U.S. Department of the Interior SALLY JEWELL, Secretary
}

\section{U.S. Geological Survey \\ Suzette M. Kimball, Acting Director}

\author{
U.S. Geological Survey, Reston, Virginia: 2015
}

For more information on the USGS - the Federal source for science about the Earth, its natural and living resources, natural hazards, and the environment—visit http://www.usgs.gov or call 1-888-ASK-USGS.

For an overview of USGS information products, including maps, imagery, and publications, visit http://www.usgs.gov/pubprod/.

Any use of trade, firm, or product names is for descriptive purposes only and does not imply endorsement by the U.S. Government.

Although this information product, for the most part, is in the public domain, it also may contain copyrighted materials as noted in the text. Permission to reproduce copyrighted items must be secured from the copyright owner.

Suggested citation:

Fulford, J.M., and Kimball, Scott, 2015, Hydraulic laboratory testing of SonTek-IO Plus: U.S. Geological Survey Open-File Report 2015-1139, 16 p., http://dx.doi.org/10.3133/ofr20151139.

ISSN 2331-1258 (online) 


\section{Contents}

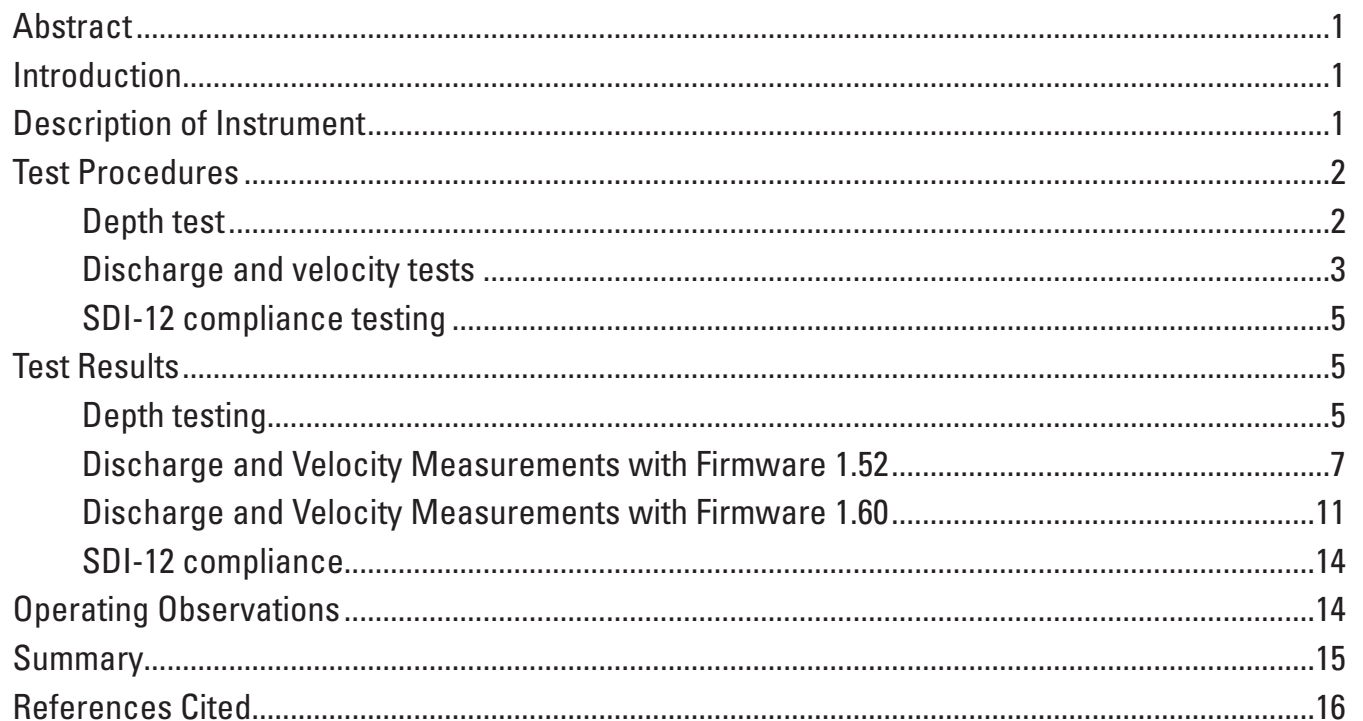

\section{Figures}

1. Photo of SonTek-IQ Plus on office table without power and communication cable.........2

2. Photo of custom angle mount on instrument arm with SonTek-IO Plus installed on mount

3. Photo of SonTek-IQ Plus sensor mounted to Hydraulic Laboratory tilting flume bottom and three SonTek-IQ Plus sensors mounted side by side on Hydraulic Laboratory tilting flume bottom ....

4. Graph showing difference between depth readings measured by SonTek-IO Plus and laboratory reference for 0 and \pm 5 degrees pitch-and-roll angles for depth below water surface from 0 to 7 feet

5. Graph showing difference between depth readings measured by SonTek-IO Plus and laboratory reference for 0 and \pm 5 degrees pitch-and-roll angles for depth below water surface from 0 to 7 feet

6. Graph showing difference between depth readings measured by SonTek-IO Plus and laboratory reference for 0 and \pm 5 degrees pitch-and-roll angles for depth below water surface from 0 to 7 feet

7. Graph showing difference between depth readings measured by SonTek-IO Plus and laboratory reference for 0 and \pm 10 degrees pitch-and-roll angles for depth below water surface from 0 to 7 feet

8. Graph showing percent difference in discharge between SonTek-I0 Plus using firmware 1.52 and SonTek's "theoretical" computation method and FlowTracker using midsection computation method for discharges from approximately 7 to 36 cubic feet per second.

9. Graphs showing velocity profiles measured by SonTek-IO Plus and FlowTracker for average stream-wise velocities of $0.5,1.1$, and 2.0 feet per second

10. Graphs showing velocity profiles measured by SonTek-I0 plus using firmware 1.52 and FlowTracker for average stream-wise velocities of $0.7,1.4$, and 3.2 feet per second 
11. Graph showing percent velocity difference between the SonTek-IO Plus using firmware 1.52 and the FlowTracker for velocity profiles measured for average stream-wise velocities of $0.5,1.1$, and 2.0 feet per second plotted with the I0 Plus accuracy.

12. Graphs showing percent velocity difference between the SonTek-IO Plus using firmware 1.52 and the FlowTracker for velocity profiles measured for average stream-wise velocities of $0.7,1.4$, and 3.2 feet per second plotted with the I0 Plus accuracy.

13. Graph showing percent difference between SonTek-I0 Plus using firmware 1.52 and FlowTracker mean-profile velocity at various mean-flow velocities from 0.5 to about 3.25 feet per second.

14. Graph showing percent difference in discharge between SonTek-I0 Plus using firmware 1.60 and SonTek's "theoretical" computation method and FlowTracker using midsection method for discharges from approximately 7 to 36 cubic feet per second

15. Graphs showing velocity profiles measured by SonTek-IO Plus using firmware 1.60 and FlowTracker for average stream-wise velocities of 0.7, 1.6, and 2.7 feet per second

16. Graphs showing percent velocity difference between the SonTek-I0 Plus using firmware 1.60 and the FlowTracker for velocity profiles measured for average stream-wise velocities of $0.7,1.6$, and 2.7 feet per second plotted with the I0 Plus accuracy.

17. Graph showing percent difference between SonTek-I0 Plus using firmware 1.60 and FlowTracker mean-profile velocity at various mean-flow velocities from 0.7 to about 2.7 feet per second..

18. Screen shot of SonTek-I0 Plus software showing the setup menu.

19. Screen shot of tilt warning given when SonTek-IO Plus is installed with a tilt greater than 5 degrees

\section{Tables}

1. Selected manufacturer's specifications for the SonTek-IO Plus.

2. Discharge measured with SonTek-I0 Plus with firmware 1.52 using SonTek's "theoretical" computation method compared with traditional discharge measurement made with FlowTracker using the midsection computation method

3. Mean-profile velocity measured with SonTek-I0 Plus using firmware 1.52 and with FlowTracker.

4. Mean-profile velocity measured with SonTek-I0 Plus using firmware 1.60 and with FlowTracker.

5. Mean-profile velocity measured with SonTek-IO Plus using firmware 1.60 and with FlowTracker. 


\section{Conversion Factors}

Inch/Pound to SI

\begin{tabular}{lcl}
\hline \multicolumn{1}{c}{ Multiply } & By & \multicolumn{1}{c}{ To obtain } \\
\hline inches (in.) & Length & \\
foot (ft) & 2.54 & centimeter $(\mathrm{cm})$ \\
\hline & 0.3048 & meter $(\mathrm{m})$ \\
\hline square foot $\left(\mathrm{ft}^{2}\right)$ & Area & \\
square foot $\left(\mathrm{ft}^{2}\right)$ & 929.0 & square centimeter $\left(\mathrm{cm}^{2}\right)$ \\
\hline & 0.09290 & square meter $\left(\mathrm{m}^{2}\right)$ \\
\hline cubic foot $\left(\mathrm{ft}^{3}\right)$ & Volume & \\
\hline & 0.02832 & cubic meter $\left(\mathrm{m}^{3}\right)$ \\
\hline foot per second $(\mathrm{ft} / \mathrm{s})$ & Flow rate & \\
cubic foot per second $\left(\mathrm{ft}^{3} / \mathrm{s}\right)$ & 0.3048 & meter per second $(\mathrm{m} / \mathrm{s})$ \\
\hline
\end{tabular}

Temperature in degrees Celsius $\left({ }^{\circ} \mathrm{C}\right)$ may be converted to degrees Fahrenheit $\left({ }^{\circ} \mathrm{F}\right)$ as follows:

${ }^{\circ} \mathrm{F}=\left(1.8 x^{\circ} \mathrm{C}\right)+32$ 



\title{
Hydraulic Laboratory Testing of SonTek-IO Plus
}

\author{
By Janice M. Fulford and Scott Kimball
}

\section{Abstract}

The SonTek-IQ Plus (IQ Plus) is a bottom-mounted Doppler instrument used for the measurement of water depth and velocity. Evaluation testing of the IQ Plus was performed to assess the accuracy of water depth, discharge, and velocity measurements. The IQ Plus met the manufacturer's specifications and the U.S. Geological Survey (USGS) standard for depth accuracy measurement when the unit was installed, according to the manufacturer's instructions, at 0 degrees pitch and roll. However, because of the limited depth testing conducted, the depth measurement is not recommended as a primary stage measurement. The IQ Plus was tested in a large indoor tilting flume in a 5-foot (ft) wide, approximately 2.3-ft deep section with mean velocities of $0.5,1,2$, and $3 \mathrm{ft}$ per second. Four IQ Plus instruments using firmware 1.52 tested for water-discharge accuracy using SonTek's “theoretical" discharge method had a negative bias of -2.4 to -11.6 percent when compared with discharge measured with a SonTek Flow Tracker and the midsection discharge method. The IQ Pluses with firmware 1.52 did not meet the manufacturer's specification of $+/-1$ percent for measuring velocity. Three IQ Pluses using firmware 1.60 and SonTek's "theoretical" method had a difference of -1.6 to -7.9 percent when compared with discharge measured with a SonTek FlowTracker and the midsection method. Mean-velocity measurements with firmware 1.60 met the manufacturer's specification and Price Type AA meter accuracy requirements when compared with FlowTracker measurements. Because of the instrument's velocity accuracy, the SonTek-IQ Plus with firmware 1.60 is considered acceptable for use as an index velocity instrument for the USGS. The discharge computed by the SonTek-IQ Plus during the tests had a substantial negative bias and will not be as accurate as a discharge computed with the index velocity method. The USGS does not recommend the use of undocumented computation methods, such as SonTek's "theoretical" method for computing discharge.

\section{Introduction}

The U.S. Geological Survey (USGS) Hydrologic Instrumentation Facility (HIF) evaluates the performance of instruments and equipment that are used to directly measure hydrologic data. Instrument and equipment evaluations are conducted primarily to determine if particular sensors would be suitable for use by USGS personnel for hydrologic data collection. Sensors are evaluated against the manufacturer's stated specifications for accuracy and resolution and any relevant USGS accuracy requirements.

The USGS uses several types of in-situ, fixed-mounted acoustic Doppler velocity meters (ADVMs) for measurement of water velocities. Fixed mounted ADVMs are mounted either on the side or bottom of the stream or canal. These instruments are used to measure a representative stream velocity that is used by the index velocity method (Levesque and Oberg, 2012) to compute discharge. This report documents testing of SonTek-IQ Plus (IQ Plus) by the USGS HIF for compliance with the manufacturer's depth, velocity, and discharge accuracy specifications and with the Serial Digital Interface at 1200 baud (SDI-12) communication standard (SDI-12 Support Group, 2013). Initial discharge and velocity testing used SonTek-IQ Plus firmware 1.52. After discharge and velocity testing was completed, firmware 1.60 was released in June 2013 and testing was repeated with firmware 1.60. Results for both discharge and velocity tests are presented in the report. The results are applicable only to the instrument versions tested and may or may not be representative of the results obtained with future versions.

\section{Description of Instrument}

The SonTek-IQ Plus (fig. 1) is designed for use as a lowprofile, bottom-mounted velocity and water-discharge measuring system. The instrument was designed in collaboration with California Polytechnic State University and the University of Illinois to compute discharge in irrigation canals (Cook and others, 2012). Using the velocities and depths measured by the instrument and a known cross section input by the user, the IQ Plus software can calculate discharge using either SonTek's "theoretical" model of the velocity distribution or the index velocity method preferred by the USGS (Levesque and Oberg, 2012). The USGS does not recommend the use of undocumented computation methods, such as SonTek's "theoretical" 
method for computing discharge. The IQ Plus measures water depth using two sensors, an upward-looking acoustic beam and a nonvented pressure sensor. The nonvented pressure sensor is used to measure depth when no data are available from the vertical acoustic beam. Because the pressure sensor is not vented to the atmosphere, it will need to be adjusted for atmospheric pressure at periodic intervals by the user. Alternatively, the instrument can be configured to use the acoustic vertical beam to perform regular, automatic calibrations of the pressure sensor.

The IQ Plus uses monostatic, acoustic transducers with the Doppler shift principal to measure water velocity. Doppler shift occurs when an acoustic signal reflecting off particles moving with the water shifts the frequency of the transmitted signal. The reflected signal is shifted by a frequency that is proportional to the speed of the acoustic scatters in the water. The frequency is shifted higher for particles moving towards the transducer and lower for particles moving away from the transducer. Because the Doppler shift is also a function of the sound speed of the water, knowledge of water temperature and salinity are important to obtain accurate velocity measurements. A detailed explanation of acoustic Doppler velocity profile measurement principals is presented by Mueller and others (2013).

The IQ Plus measures velocity with four acoustic transducers with profiling beams that are angled upstream, downstream, and at right and left skew angles. The upstream- and downstream-facing beams are oriented along the stream axis and are angled 25 degrees from the vertical. The skew beams are oriented 60 degrees from the center-stream axis and are angled 60 degrees from the vertical. For each pair of profiling beams, the sensor automatically selects between three types of acoustic pulses or pings (coherent, incoherent, and broadband), depending on the flow conditions (Xylem, 2012). The automatic selection of the acoustic pulsing scheme is marketed as "SmartPulse ${ }^{\mathrm{HD}}$ " in the manufacturer's sales brochures (SonTek, 2011). The IQ Plus manual does not have any option to turn off the "SmartPulse ${ }^{\mathrm{HD}}$ " or to change acoustic operation modes.

The velocity is profiled by the IQ Plus over the flow depth in multiple depth cells by measuring the Doppler shift of the transmitted acoustic signal in each depth cell. The velocity profiling depth is dynamically adjusted based on the water depth measured by the vertical acoustic beam. The profiling range is also automatically limited to the cell farthest from the transducer with an acceptable signal-to-noise ratio (SNR) if the next farthest cell has a SNR that is too low for a reliable velocity measurement. The limit of the profiling range is recorded for each sample. The velocity measurement is automatically compensated for water-density changes due to temperature in fresh water.
Water salinity must be defined by the user. Selected specifications from the manufacturer's literature are listed in table 1 (Xylem Incorporated, 2012).

\section{Test Procedures}

The IQ Plus was tested for the ability to accurately measure stage, discharge, velocity, and for compliance with version SDI-12 1.3 (SDI-12 Support Group, 2013). Four different instruments were tested - one instrument, loaned by the vendor, and three subsequentially purchased instruments. All instruments were configured to use the default units of feet (ft). SonTek's "theoretical" discharge measurement method was tested to access the accuracy of the method. This method is not used by the USGS because it is not well documented and its accuracy is unknown. Because the index velocity discharge method is well documented and relies on the mean velocity, it was not tested.

\section{Depth test}

The depth accuracy test was performed in the jet tank at the USGS HIF Hydraulics Laboratory to test the effect of pitch-and-roll angles on the depth measurement. This facility has a mechanical arm that can be accurately positioned (raised and lowered) to depths ranging from 0 to $7 \mathrm{ft}$ with a measurement resolution of $0.01 \mathrm{ft}$. A custom angle mount (fig. 2) was made for the IQ Plus that allowed the device to be tilted forward and backward (pitch) or side to side (roll). The angle mount was used to test the IQ Plus' ability to measure depth correctly for various pitch-and-roll angles. The depth accuracy test did not test either the pressure sensor or the vertical acoustic depth sensor over their entire operating temperature and depth range.

Depth testing was initially conducted using the loaned instrument (serial number (sn) IQ1151134) using

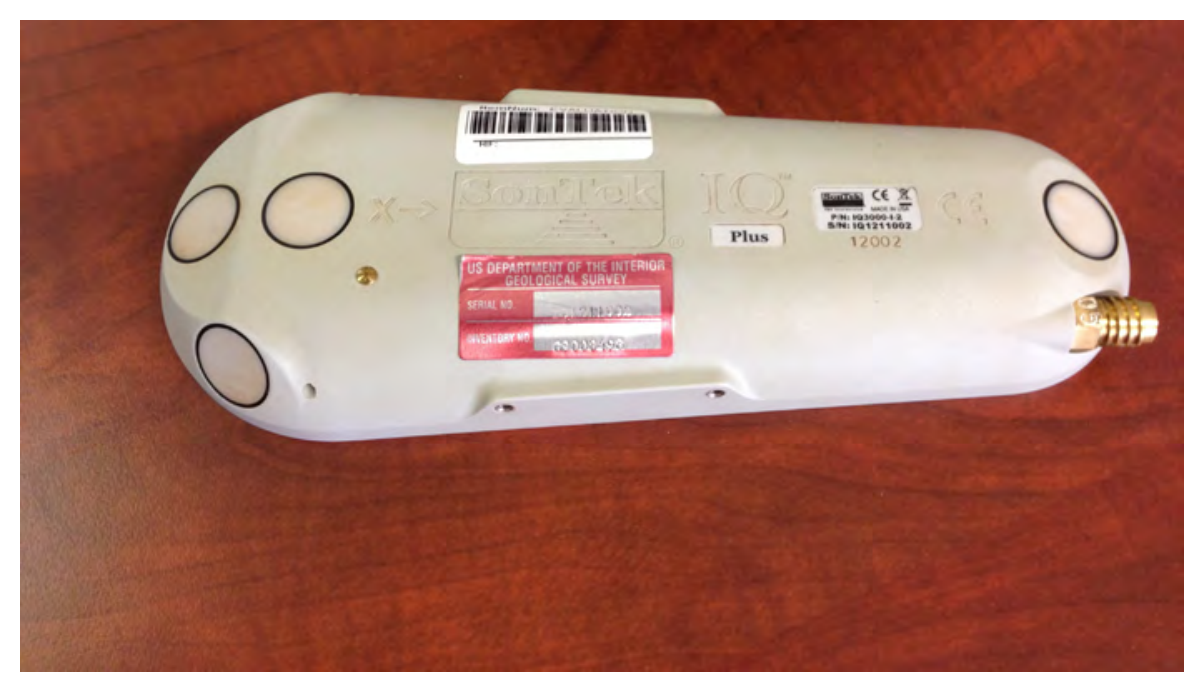

Figure 1. Photo of SonTek-IQ Plus on office table without power and communication cable. 
Table 1. Selected manufacturer's specifications for the SonTek-I0 Plus.

\begin{tabular}{|c|c|}
\hline Feature & Specification \\
\hline \multicolumn{2}{|c|}{ Velocity Measurement } \\
\hline Sampling range & 0.3 to 16 feet \\
\hline Number of cells & Up to 100 \\
\hline Cell size & 0.8 to 4 inches \\
\hline Range & 16 feet per second \\
\hline Resolution & 0.0003 feet per second \\
\hline Accuracy & $\begin{array}{l}1 \text { percent of reading, } 0.0167 \text { feet } \\
\text { per second }\end{array}$ \\
\hline \multicolumn{2}{|c|}{ Water Level } \\
\hline Vertical acoustic beam range & 0.2 to 16 feet \\
\hline Vertical acoustic beam accuracy & $\begin{array}{l}0.1 \text { percent of reading or } 0.01 \\
\text { feet, whichever is greater }\end{array}$ \\
\hline Pressure sensor range & $\begin{array}{l}98 \text { feet of water, } 42 \text { pounds per } \\
\text { square inch }\end{array}$ \\
\hline Pressure sensor accuracy & 0.1 percent full scale \\
\hline \multicolumn{2}{|c|}{ Acoustics } \\
\hline Frequency & 3.0 megahertz \\
\hline $\begin{array}{l}\text { Blanking distance from trans- } \\
\text { ducers }\end{array}$ & 0.8 inches \\
\hline Beam width & 1.4 degrees \\
\hline \multicolumn{2}{|c|}{ Temperature } \\
\hline Operating/storage & -5 to 60 degrees Celsius \\
\hline Sensor accuracy & \pm 0.2 degrees Celsius \\
\hline Sensor/resolution & \pm 0.01 degrees Celsius \\
\hline \multicolumn{2}{|c|}{ Other } \\
\hline Tilt sensor accuracy & \pm 1.0 degrees \\
\hline Communications & $\begin{array}{l}\text { RS232, SDI-12, Modbus, Ana- } \\
\quad \log \text { (via optional flow display) }\end{array}$ \\
\hline Data storage & 4 gigabytes \\
\hline Power input & $8-15$ voltage direct current \\
\hline Power consumption & $\begin{array}{l}0.5-1.0 \text { watts ( } 0.02 \text { watts } \\
\text { when idle) }\end{array}$ \\
\hline
\end{tabular}

firmware 1.52. Readings were recorded at pitch angles of -20 , $-10,-5,0,5,+10$, and 20 degrees for 0 -degree roll angle and at roll angles of $-20,-10,-5,0,5,+10$, and 20 degrees for 0 -degree pitch angle at depth intervals of $1 \mathrm{ft}$ from 1 to $7 \mathrm{ft}$. Further testing was performed on three additional instruments (sns IQ1211002, IQ1211003, and IQ1211004) using firmware 1.60 at level and at pitch angles of 0,5 , and -5 degrees, and at roll angles of 0,5 , and -5 degrees, at intervals of $1 \mathrm{ft}$ from 1 to $7 \mathrm{ft}$ in depth. IQ Plus software instrument "standard settings" for depth testing were set to 0 parts per thousand (ppt) water salinity, 10-second (s) sample duration, 10-s sample interval, and profile recording.

The angle mount was positioned to a test angle prior to attaching the IQ Plus. The IQ Plus was attached to the mount by using the mounting locations provided on the IQ Plus. A

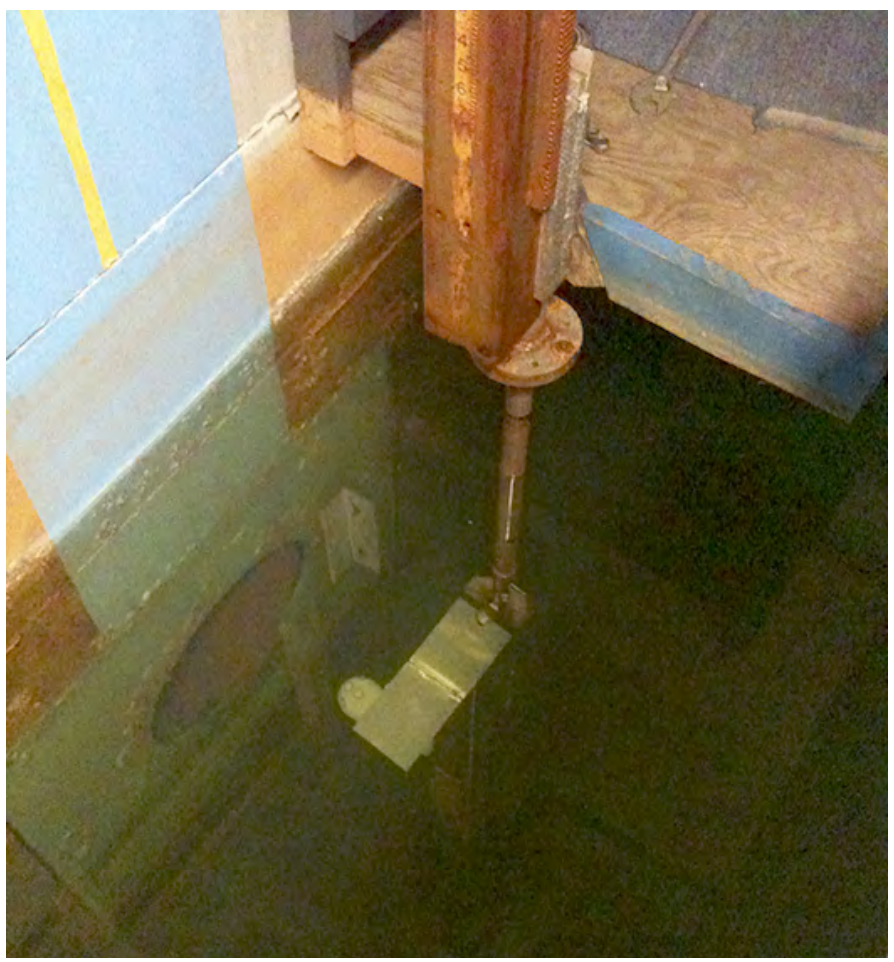

Figure 2. Custom angle mount on instrument arm with SonTek-IO Plus installed on mount.

Pro 360 Digital Protractor (Mitutoyo Inc., 2003) with a stated accuracy of \pm 0.1 degree was used to set the mount's pitch or roll angle and to verify the final pitch or roll angle of the mounted instrument. The protractor reading was compared to the pitch-and-roll angle given by the IQ Plus. For 0-degree angles of pitch and roll, the IQ Plus was leveled in the mount and then lowered until it reported a depth of $1 \mathrm{ft}$. An engineer's measuring tape was then used to verify that $1 \mathrm{ft}$ of water was over the transducer. For all other angles of pitch and roll, getting an accurate tape down was impractical and the unit was lowered until the IQ Plus gave a reading of $1 \mathrm{ft}$. At the initial 1 -ft depth, measurements were recorded at 10-s intervals for about 2.5 minutes or until 15 readings were obtained. The sensor continued to record measurements as it was lowered another foot to the next depth. Fifteen more readings were then recorded at the next depth. This process was repeated until the maximum depth of $7 \mathrm{ft}$ was reached. The procedure was then repeated as the unit was raised back to the surface.

\section{Discharge and velocity tests}

The discharge and velocity accuracy tests were performed in the tilting flume at the USGS Hydraulics Laboratory at the HIF. The tilting flume is $6 \mathrm{ft}$ wide, $3 \mathrm{ft}$ deep, and $250 \mathrm{ft}$ long and can be tilted to slopes of $\leq 1$ percent. The discharge capacity is a maximum of 50 cubic feet per second $\left(\mathrm{ft}^{3} / \mathrm{s}\right)$, partially or wholly supplied by the laboratory's constant head tank. All testing was performed with the flume in a level position. The loaned sensor (sn IQ1151134) was the first sensor tested. 
It was mounted to an aluminum plate on the bottom of the channel (fig. 3) in a 5-ft-wide, contracted section of the tilting flume. Subsequently, three additional sensors (sns IQ1211002, IQ1211003, and IQ1211004) were tested as a group in the same section of the tilting flume. The three sensors were mounted 8 inches apart (fig. 3 ) and were operated one at a time to prevent them from acoustically interfering with each other's measurement. The three sensors were initially tested using SonTek-IQ Plus firmware 1.52 and subsequently retested using firmware 1.60. Regardless of the firmware version, IQ Plus software instrument "standard settings" for discharge and velocity testing were set to 0 -ppt water salinity, 10-s sample duration, 10-s sample interval, and profile recording. The IQ Plus software was configured to compute the discharge from its velocity measurements by entering the flume crosssection dimensions into the Smart Page channel shape section and using the defaults in the Flow Page section: equation type of "Theoretical," velocity type of "Main Vx," velocity offset of 0.00 , velocity coefficient of 1.00 , and stage coefficient of 0.00 . The software defaults for the "total volume" settings were used.

IQ Plus equation type indicates the method used to determine discharge. However, discharge computation methods are only vaguely described in the IQ Plus manual. According to the manual, the "Theoretical" equation type uses a power-law velocity profile model with a $1 / 6$ exponent, the user-entered channel geometry data, and the sensor's measured velocities and depths to compute discharge.

Four flume discharges were used to compare the IQ Plus with discharges and velocities measured by a SonTek FlowTracker (sn P1515). For the initial test with the loaner instrument, tested discharge regimes had mean velocities of $0.5,1.1$, and $2.0 \mathrm{ft}$ per second (ft/s) and flow depths of 2.24 , 2.48 , and $2.16 \mathrm{ft}$. For the three sensors tested as a group, the tested discharge regimes had target mean velocities of $0.5,1.5$ and $3.0 \mathrm{ft} / \mathrm{s}$ and a target flow depth of $2.25 \mathrm{ft}$. Discharge and velocity profiles were measured for each flume discharge.

Reference discharges and velocities were measured with the SonTek FlowTracker. These measurements were made with FlowTracker firmware version 3.7 and software version 2.30. SonTek FlowTrackers have a manufacturer's specified velocity accuracy of \pm 1 percent of measured velocity plus \pm 0.25 centimeter per second (SonTek/YSI, 2007).

The FlowTracker measurement cross section was located $2 \mathrm{ft}$ upstream of the SonTek-IQ Plus instruments. The SonTek FlowTracker discharge was computed from velocities measured at the 0.2 and 0.8 depth sampling locations at 0.25 - $\mathrm{ft}$ intervals and 0.5 -ft intervals across the flume width using the midsection method (Turnipseed and Sauer, 2010) for the initial test and for the group tests, respectively. A FlowTracker discharge measurement was made before and after the measurement of the velocity profile with the FlowTracker and the discharge measurement by the IQ Plus. The two FlowTracker discharge measurements were averaged for comparison with the discharge calculated by the IQ Plus.

The FlowTracker was also used to measure reference velocity profiles in front of each IQ Plus. At each observation depth, 401 -second velocities were made by the FlowTracker and averaged. Velocities were measured at nine depths, equally spaced over the total flow depth and $2 \mathrm{ft}$ in front of each IQ Plus. The velocity profile data collected by the IQ Plus for each depth cell included the "center" and "skew" cell velocities and cell depth, as well as information on the "center" and "skew" cell ping method, pulse length, and blanking distance. Because the IQ Plus measured 10-s samples, the FlowTracker profile velocities were compared to the time average of four IQ Plus "center" cell velocities measured at the corresponding FlowTracker measurement depth and sample time.
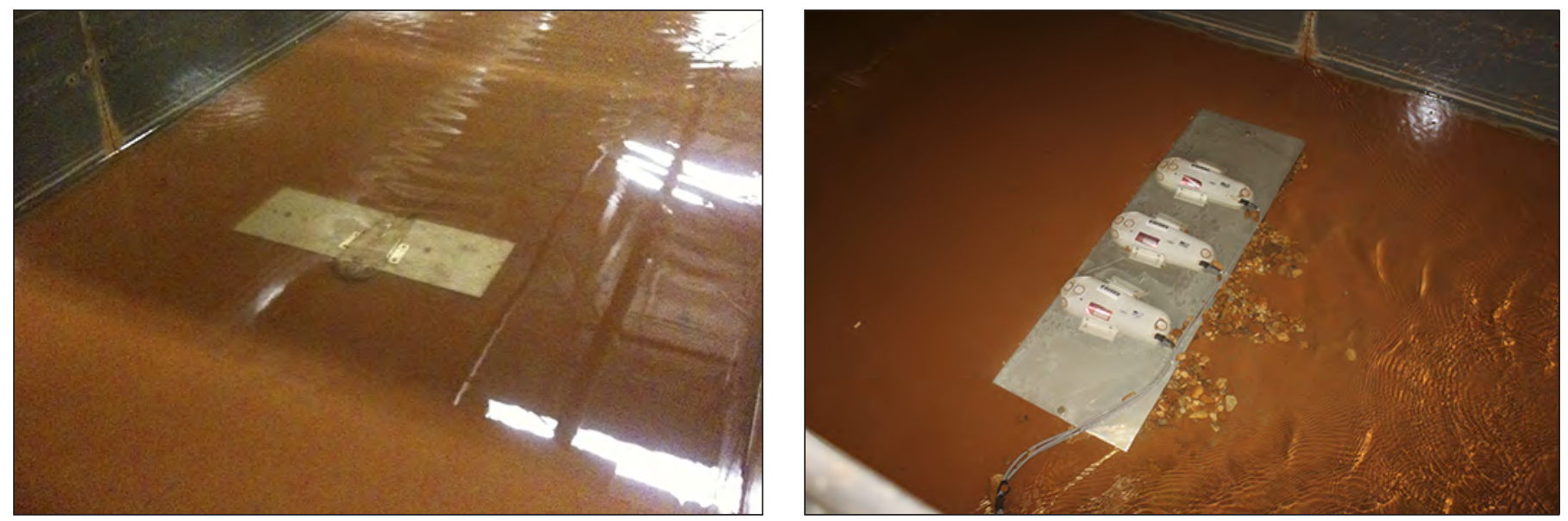

Figure 3. SonTek-IO Plus sensor (serial number (sn) I01151134) (left photo) mounted to Hydraulic Laboratory tilting flume bottom and three SonTek-IO Plus sensors (sns I01211002, I01211003, and IQ1211004) (right photo) mounted side by side on Hydraulic Laboratory tilting flume bottom. 


\section{SDI-12 compliance testing}

The SDI-12 verification test was performed using an NR Systems SDI-12 verifier and running the standard SDI-12 verifier test for version 1.3 (SDI-12 SupportGroup, 2013). The USGS commonly deploys sensors that use SDI-12 communication protocol because of the protocol's low power consumption and standard commands. The NR Systems verifier tests for compliance to timing and commands used by the standard and does not test for electrical compliance to the standard. No testing for electrical compliance to the standard was done.

\section{Test Results}

Test results are presented in tables and charts for depth testing, discharge, and velocity testing with firmware 1.52, discharge and velocity testing for firmware 1.60, and for SDI-12 testing. Values measured by the IQ Plus instruments and the reference instruments and percent differences between the IQ Plus and references are plotted for the depth, discharge, and velocity testing. Some plots include either the manufacturer's accuracy specifications or USGS criteria.

\section{Depth testing}

Figures 4, 5, 6, and 7 show the absolute differences plus 0.0001 between each IQ Plus and the laboratory stage reference for various pitch-and-roll angles over the measured depths. A value of 0.0001 was added to each absolute difference to allow plotting of all differences on the semilogarithm plot. Also plotted in figures 4, 5, 6, and 7 is the manufacturer's accuracy to a resolution of $0.01 \mathrm{ft}$. Depth differences are plotted in figures 4 through 6 for pitch-and-roll angles between \pm 5 degrees for sns IQ1211002, IQ1211003, and IQ1211004. Figure 7 has depth differences plotted for pitch-and-roll angles between \pm 10 degrees for sn IQ1151134. Depths were grossly in error for angles exceeding \pm 10 degrees. The IQ Plus depth readings were within the $\pm 0.01 \mathrm{ft}$ of the laboratory depth reference for pitch-and-roll angles of 0 degrees. All depth measurements for pitch-and-roll angles of 0 degrees met the manufacturer's accuracy specification and USGS requirements for stage measurements for the 0-to-7-ft range tested. Sensitivity to pitch-and-roll angles varied across the instruments tested. One instrument, sn IQ1211002, was more frequently outside $\pm 0.01 \mathrm{ft}$ of the laboratory depth reference for pitch-and-roll angles of 5 degrees than the other tested sensors. The USGS requirements state that stage (or depth) measurements are \pm 0.2 percent of reading or $0.01 \mathrm{ft}$, whichever is larger (U.S. Geological Survey, 1996). When the instrument was tilted more than 5 degrees during the depth tests, warnings were issued by the IQ Plus software. Depth values that were returned when the instruments were tilted more than 5 degrees were either " 0 " or very high and obviously erroneous.

The IQ Plus depth measurement may be adequate as a primary stage measurement at a USGS continuous-discharge site, providing that the water is well mixed and does not experience density stratification or changing water density due to changing salinity or sediment. However, because of

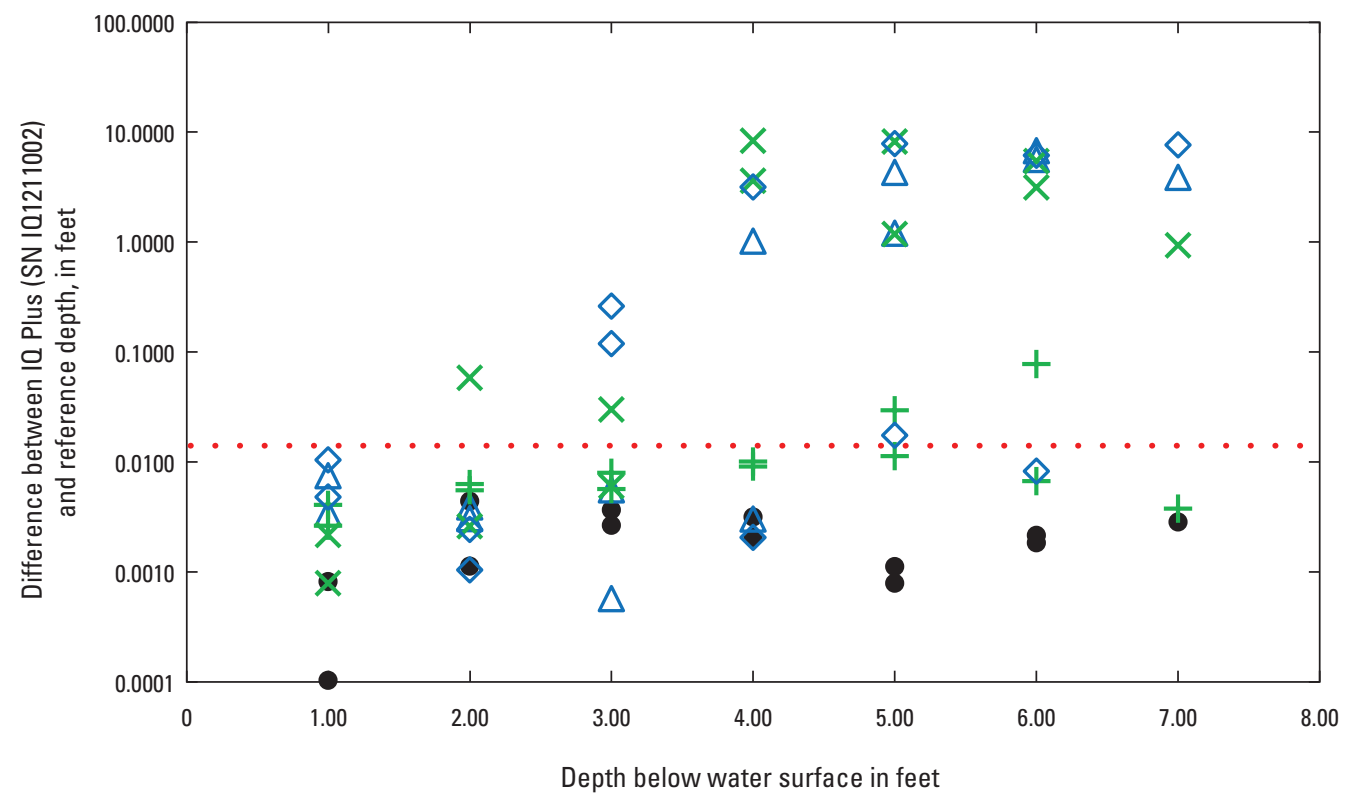

EXPLANATION

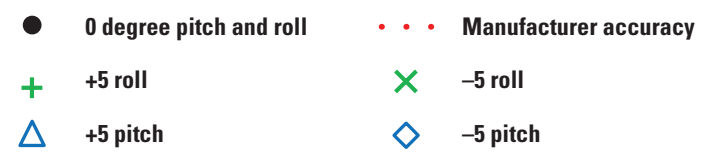

Figure 4. Difference between depth readings measured by SonTek-IO Plus (serial number I01211002) and laboratory reference for 0 and \pm 5 degrees pitch-and-roll angles for depth below water surface from 0 to 7 feet. 


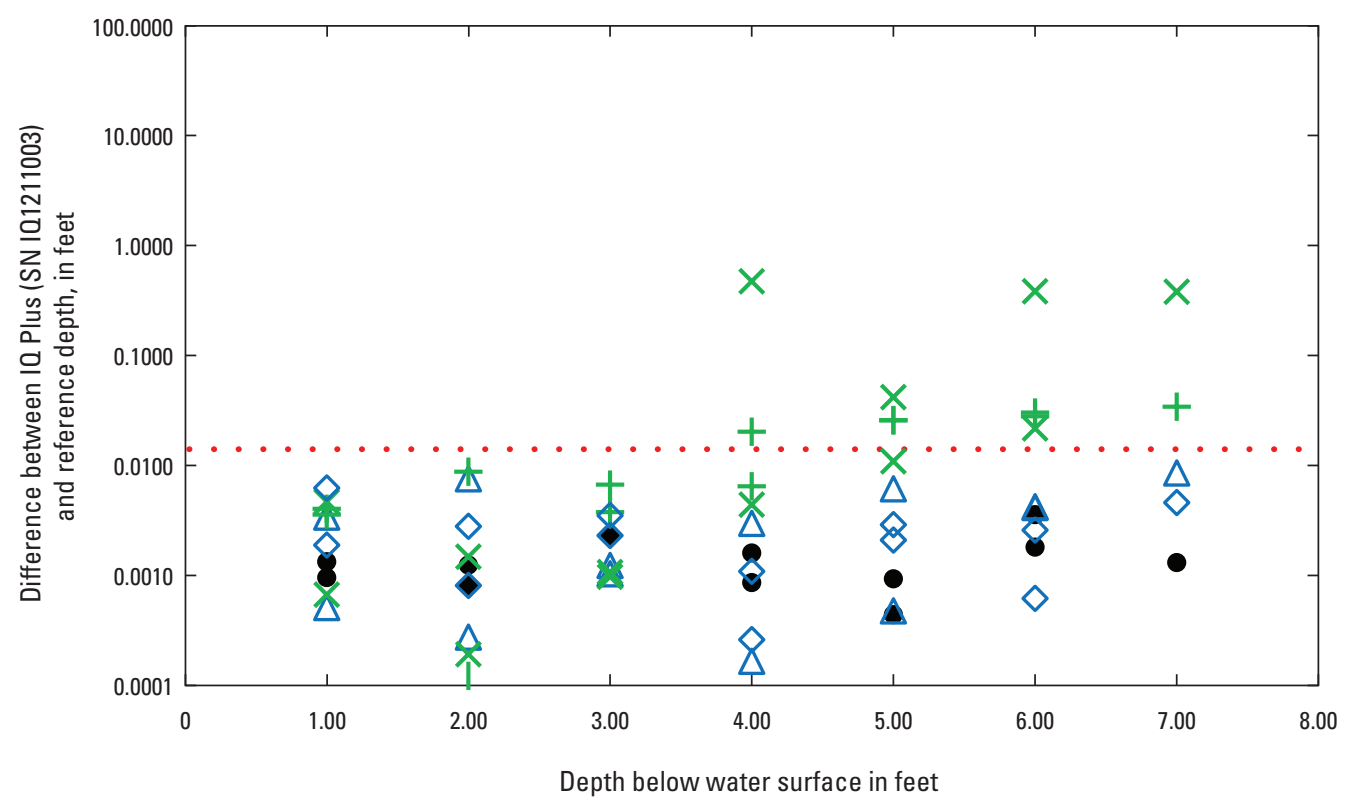

EXPLANATION

$\begin{array}{llll}- & 0 \text { degree pitch and roll } & \cdots & \text { Manufacturer accuracy } \\ +\quad+5 \text { roll } & \times & -5 \text { roll } \\ \triangle & +5 \text { pitch } & \diamond & -5 \text { pitch }\end{array}$

Figure 5. Difference between depth readings measured by SonTek-IO Plus (serial number I01211003) and laboratory reference for 0 and \pm 5 degrees pitch-and-roll angles for depth below water surface from 0 to 7 feet.

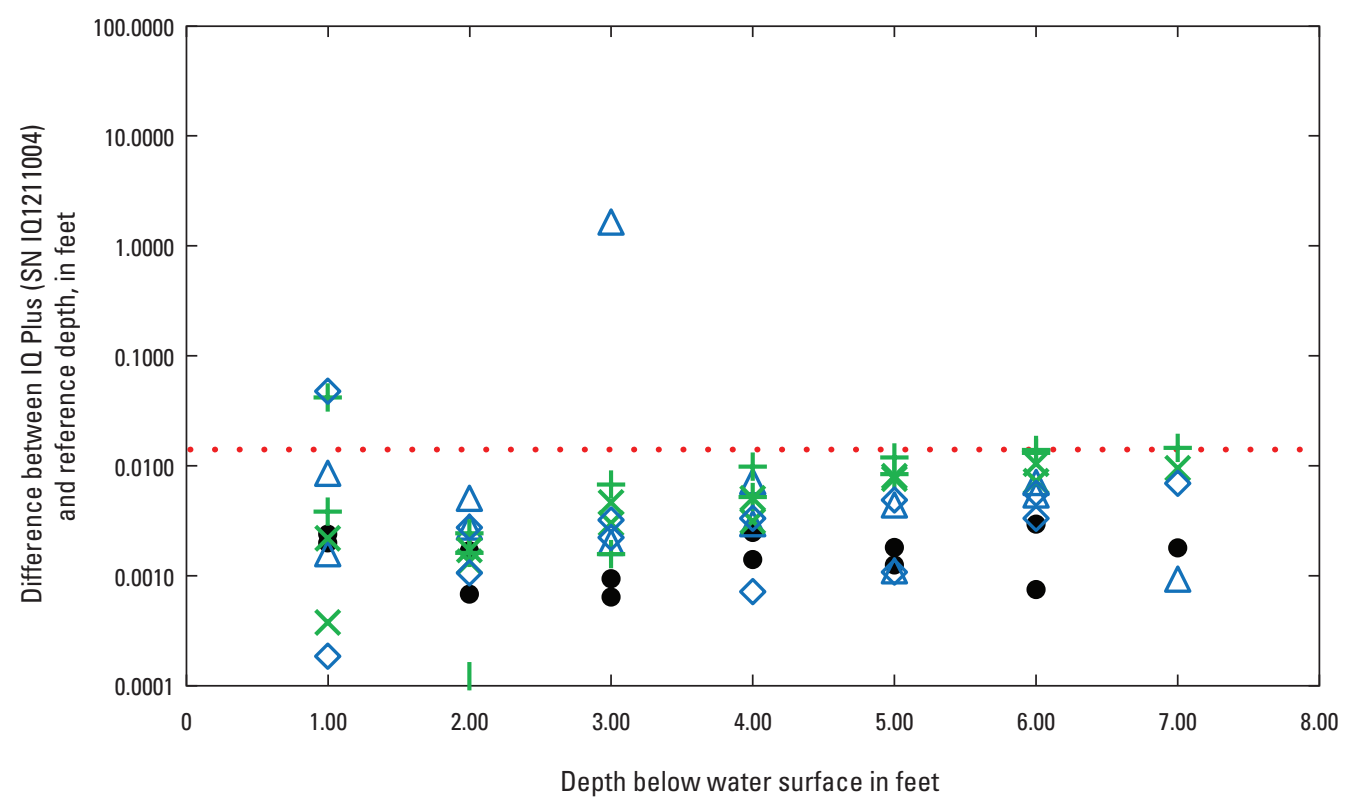

EXPLANATION

$\begin{array}{llll} & 0 \text { degree pitch and roll } & \cdots & \text { Manufacturer accuracy } \\ + & +5 \text { roll } & \times & -5 \text { roll } \\ \triangle & +5 \text { pitch } & \diamond & -5 \text { pitch }\end{array}$

Figure 6. Difference between depth readings measured by SonTek-IO Plus (serial number I01211004) and laboratory reference for 0 and \pm 5 degrees pitch-and-roll angles for depth below water surface from 0 to 7 feet. 


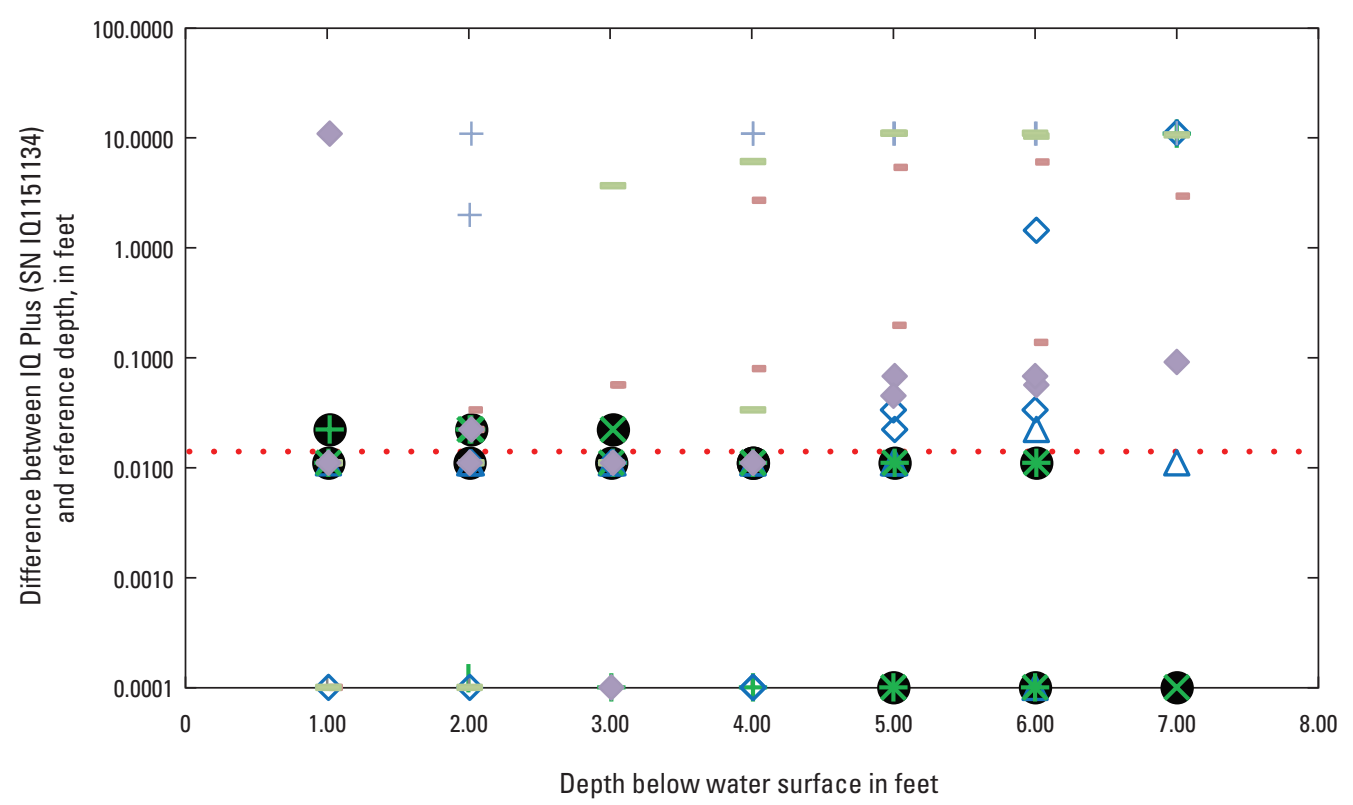

EXPLANATION

$\begin{array}{llllll} & 0 \text { degree pitch and roll } & \times & -5 \text { roll } & +10 \text { roll } \\ + & +5 \text { roll } & \diamond & -5 \text { pitch } & + & +10 \text { pitch } \\ \triangle & +5 \text { pitch } & & -10 \text { pitch } & -10 \text { roll } \\ \text { - } & \text { Manufacturer accuracy } & & & & \end{array}$

Figure 7. Difference between depth readings measured by SonTek-IO Plus (serial number I01151134) and laboratory reference for 0 and \pm 10 degrees pitch-and-roll angles for depth below water surface from 0 to 7 feet.

the limited depth testing conducted, the depth measurement is not recommended as a primary stage measurement unless the accuracy of the depth measurement is confirmed over the expected range of conditions at the deployment site with another sensor meeting USGS accuracy requirements.

\section{Discharge and Velocity Measurements with Firmware 1.52}

The discharge-measurement comparisons are shown in table 2 for the loaner instrument (sn IQ11151134) and for the three side-by-side instruments (sns IQ1211002, IQ1211003, and IQ1211004) using firmware 1.52 and the "theoretical" discharge method. The expanded uncertainty of discharge measurements by the FlowTracker was estimated based on estimated uncertainties for the steadiness of the flow ( \pm 0.5 percent flume discharge), manufacturer's stated accuracy ( \pm 1 percent), and number of velocity measurements made throughout the flow area $( \pm 0.64$ percent $)$ as \pm 1.9 percent $\left(1.9=2 \times \sqrt{0.5^{2}+0.5^{2}+0.64^{2}}\right)$, using a simplified analysis based on the Guide to the Expression of Uncertainty in Measurement (International Standards Organization, 1993). The standard uncertainty due to the number of velocity measurements in the flow area was estimated by computing the average difference between the total discharge computed using all and half (every other subarea measurement) the subarea
Table 2. Discharge measured with SonTek-IO Plus with firmware 1.52 using SonTek's "theoretical" computation method compared with traditional discharge measurement made with FlowTracker using the midsection computation method. Percent differences are computed as 100 x (IO Plus - FlowTracker)/ FlowTracker.

$\left[\mathrm{ft}^{3} / \mathrm{s}\right.$, cubic feet per second]

\begin{tabular}{|c|c|c|c|}
\hline \multicolumn{2}{|c|}{ I0 Plus } & \multirow{2}{*}{$\begin{array}{c}\text { FlowTracker } \\
\text { Discharge in } \\
\mathrm{ft}^{3} / \mathrm{s}\end{array}$} & \multirow{2}{*}{$\begin{array}{c}\text { Percent } \\
\text { difference }\end{array}$} \\
\hline Serial number & $\begin{array}{c}\text { Discharge, } \\
\text { in } \mathrm{ft}^{3} / \mathrm{s}\end{array}$ & & \\
\hline \multirow[t]{3}{*}{ IQ11151134 } & 6.37 & 6.82 & -6.6 \\
\hline & 12.9 & 13.4 & -3.7 \\
\hline & 20.2 & 21.7 & -6.9 \\
\hline \multirow[t]{3}{*}{ IQ1211002 } & 7.21 & 7.68 & -6.1 \\
\hline & 14.5 & 16.4 & -11.6 \\
\hline & 36.2 & 37.6 & -3.7 \\
\hline \multirow[t]{3}{*}{ IQ1211003 } & 7.30 & 7.68 & -4.9 \\
\hline & 16.0 & 16.4 & -2.4 \\
\hline & 34.5 & 37.6 & -8.2 \\
\hline \multirow[t]{3}{*}{ IQ1211004 } & 7.18 & 7.68 & -6.5 \\
\hline & 15.9 & 16.4 & -3.0 \\
\hline & 33.6 & 37.6 & -10.6 \\
\hline
\end{tabular}


velocity and depth measurements for discharge measurements made at mean velocities of 1 and $2 \mathrm{ft} / \mathrm{s}$. The manufacturer's accuracy was also assumed to be equal to the expanded uncertainty (twice the standard uncertainty) of the instrument's velocity measurement. The percent differences shown in table 2 were computed as $100 \mathrm{x}$ (IQ Plus - FlowTracker)/ FlowTracker. All IQ Plus instruments tested under-registered discharge when compared to the FlowTracker. The discharge bias ranged from -2.4 to -11.6 percent and averaged -6.2 percent for the test discharges. As the mean velocity increased to $3 \mathrm{ft} / \mathrm{s}$, the IQ Plus began to return "\#N/A" values for velocity in several cell locations, even though good SNR numbers (generally in the 50-dB range, much larger than the minimum required 3 decibels) were measured. The "\#N/A" values for velocity required the IQ Plus software to interpolate more of the velocity data in the vertical, possibly contributing to some of the discharge bias. There does not appear to be a trend to the bias with increasing or decreasing discharge (fig. 8).

Figure 8 also plots the IQ Plus "theoretical" discharges according to USGS criteria and includes vertical error bars of $\pm 1.9 \%$, the estimated uncertainty of the FlowTracker discharge measurement. The USGS rates discharge measurements as excellent ( $\leq 2 \%$ error), good ( $>2 \%$ and $\leq 5 \%$ error), fair $(>5 \%$ and $\leq 8 \%$ error), or poor ( $>8 \%$ error) (Nolan and Shields, 2000). IQ Plus measurements were rated based on the difference between the discharges measured by the FlowTracker and IQ Plus. None of the IQ Plus measured discharges using the "theoretical" method were rated excellent, in spite of the excellent measurement section and steadiness of the flow. Most IQ Plus discharge measurements were rated as either good (5) or fair (4). Several were rated as poor (3). The IQ Plus "theoretical" discharge measurements with firmware 1.52 have a negative bias compared to the reference FlowTracker measurement and none of the tested instruments using the "theoretical" method were within the manufacturer's suggested accuracy of 3 to 5 percent (Xylem, 2012, p. 97).

The velocity profiles measured by the IQ Plus instruments and the FlowTracker are shown in figures 9 and 10. In these figures, the center-cell velocity measurements of the IQ Plus instruments are plotted with the nearest FlowTracker measurements. Velocity profiles measured by the first instrument tested are in figure 9 and velocity profiles for the instruments tested as a group are in figure 10. Except at a few locations, the velocity profiles measured by the IQ Plus instruments generally underregistered velocity when compared to the FlowTracker. Horizontal error bars in figure 9 represent the manufacturer's stated accuracy for the instrument.

The percent velocity differences between the velocity measured by the IQ Plus and the FlowTracker are plotted in figures 11 and 12, with the IQ Plus accuracy specification. The percent velocity differences were computed as $100 \mathrm{x}$ (IQ Plus FlowTracker)/FlowTracker. The percent velocity differences for the first instrument tested are in figure 11. The red error bars represent the accuracy of the reference velocity measurement (FlowTracker). The percent velocity differences for the instruments tested in a group are in figure 12. The general negative bias of the velocity is clearly seen in all of these plots and shows that the velocity measured by the IQ Plus frequently does not meet the manufacturer's accuracy specification.

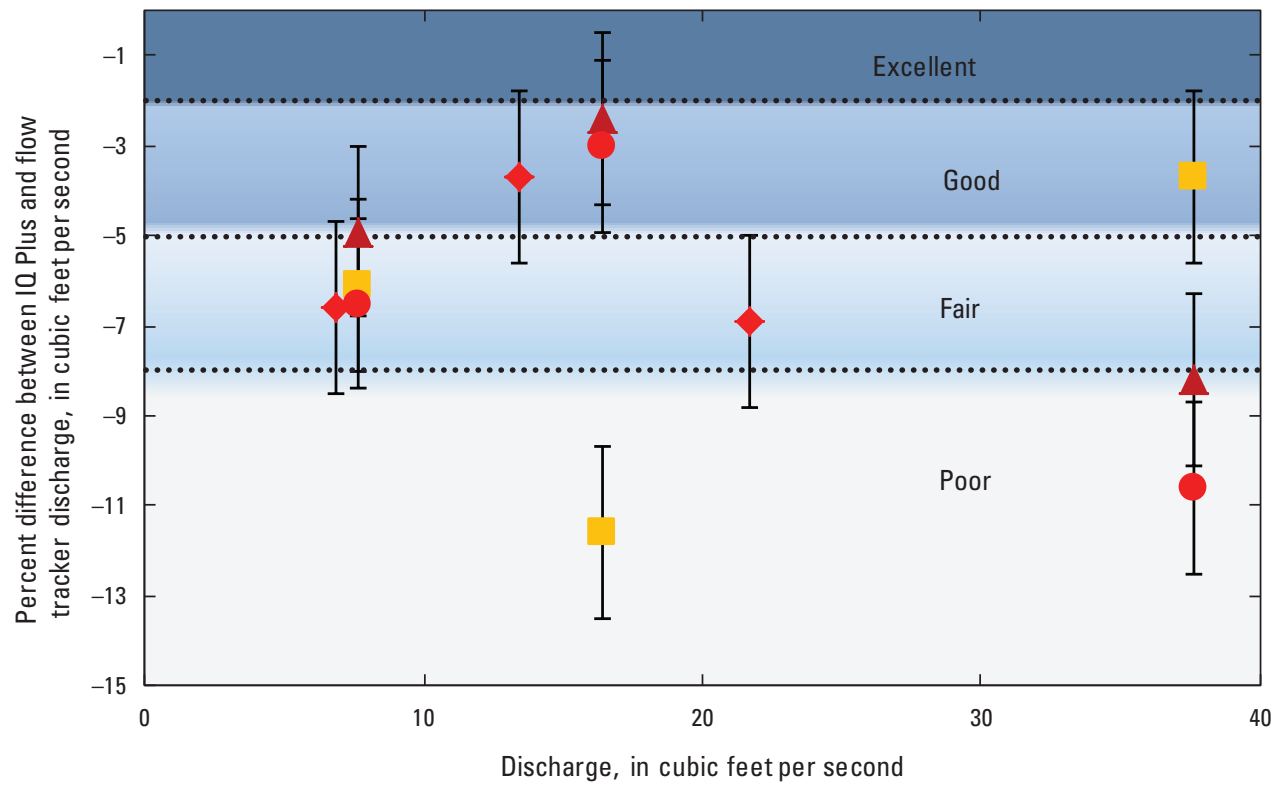

EXPLANATION

$\begin{array}{rr}101151134 & \Delta I 01211003 \\ 101211002 & \text { I01211004 }\end{array}$

Figure 8. Percent difference in discharge between SonTek-IO Plus using firmware 1.52 and SonTek's "theoretical" computation method and FlowTracker using midsection computation method for discharges from approximately 7 to 36 cubic feet per second. 

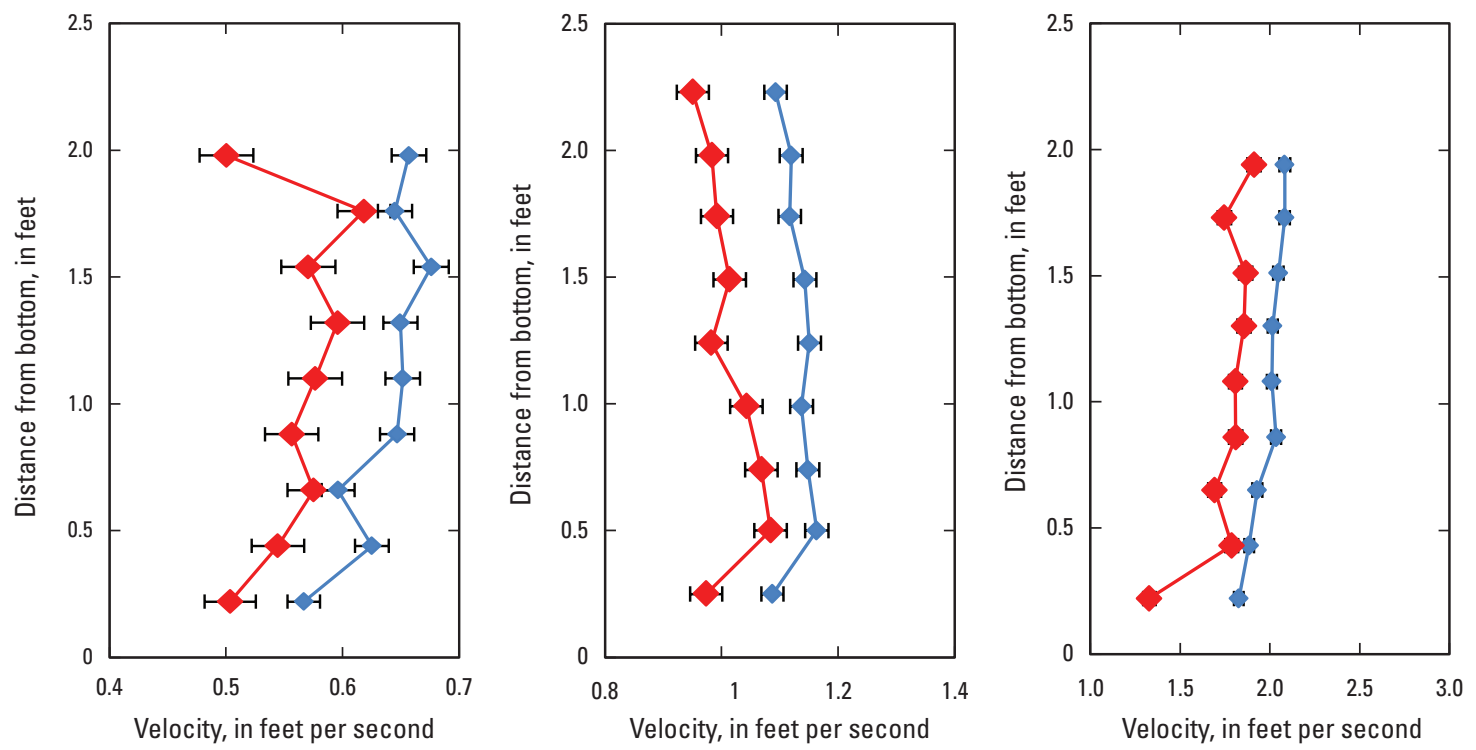

\section{EXPLANATION}

$\longrightarrow$ FlowTracker

$\multimap$ IQ Plus (I01151134)

Figure 9. Velocity profiles measured by SonTek-I0 Plus (serial number I01151134) and FlowTracker for average stream-wise velocities of $0.5,1.1$, and 2.0 feet per second (as measured by the FlowTracker).
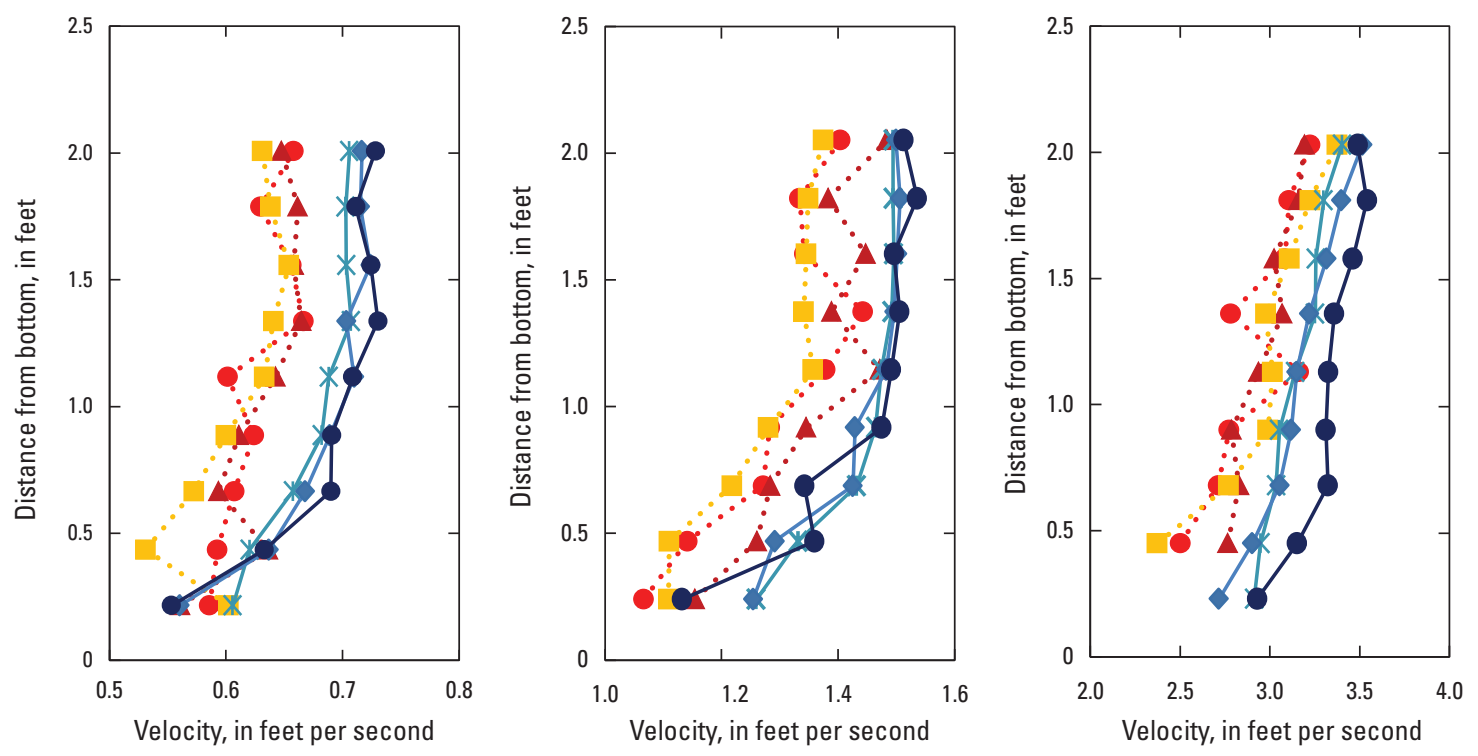

EXPLANATION

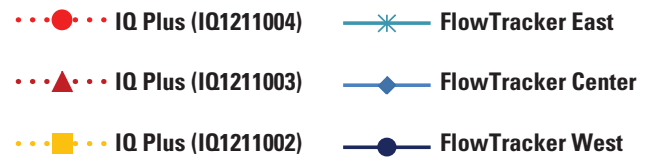

Figure 10. Velocity profiles measured by SonTek-IO plus using firmware 1.52 and FlowTracker for average stream-wise velocities of $0.7,1.4$, and 3.2 feet per second (as measured by the FlowTracker). 

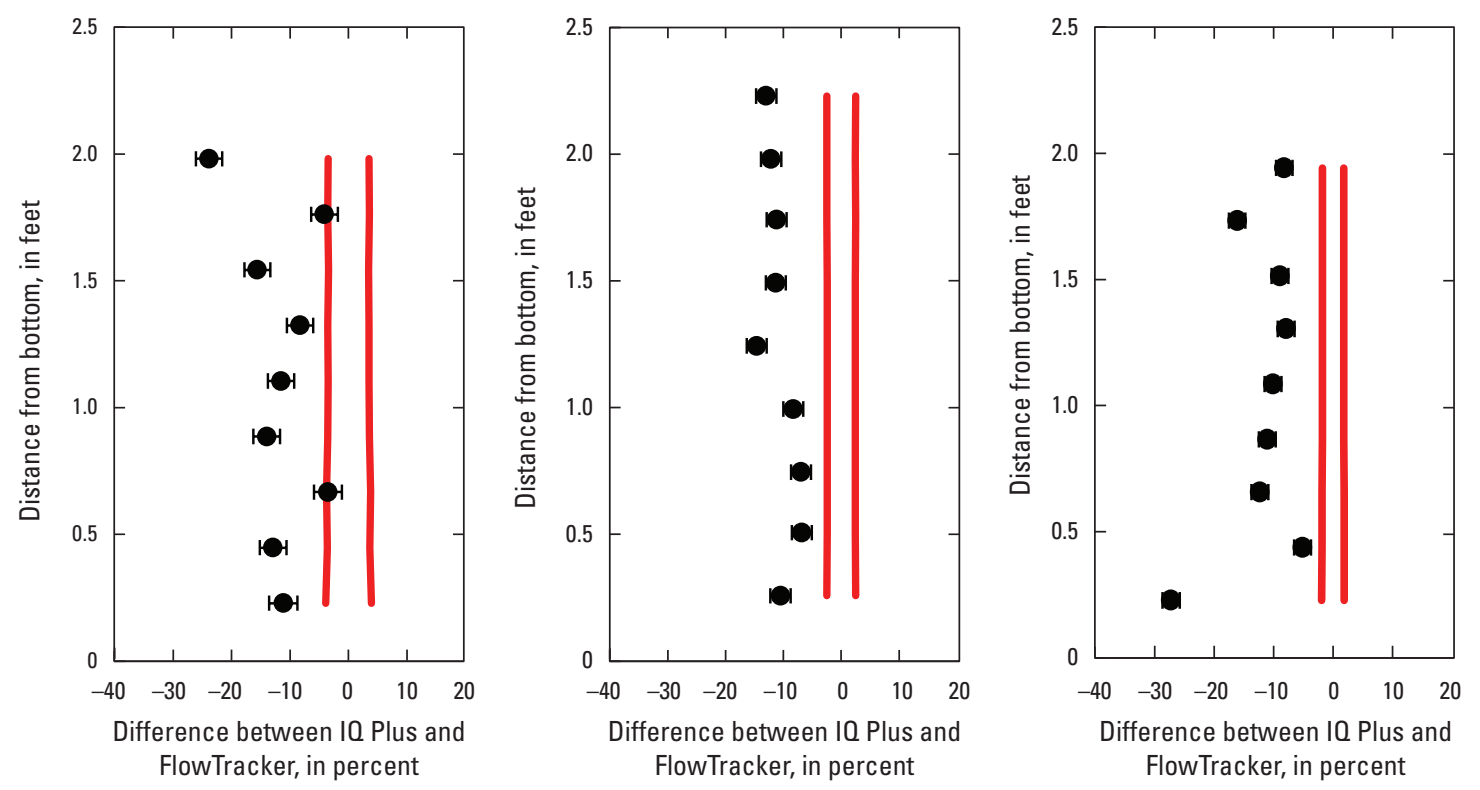

EXPLANATION

Accuracy

- IO Plus (101151134)

Figure 11. Percent velocity difference between the SonTek-IQ Plus using firmware 1.52 and the FlowTracker for velocity profiles measured for average stream-wise velocities of $0.5,1.1$, and 2.0 feet per second (as measured by the FlowTracker) plotted with the IO Plus accuracy (red lines).
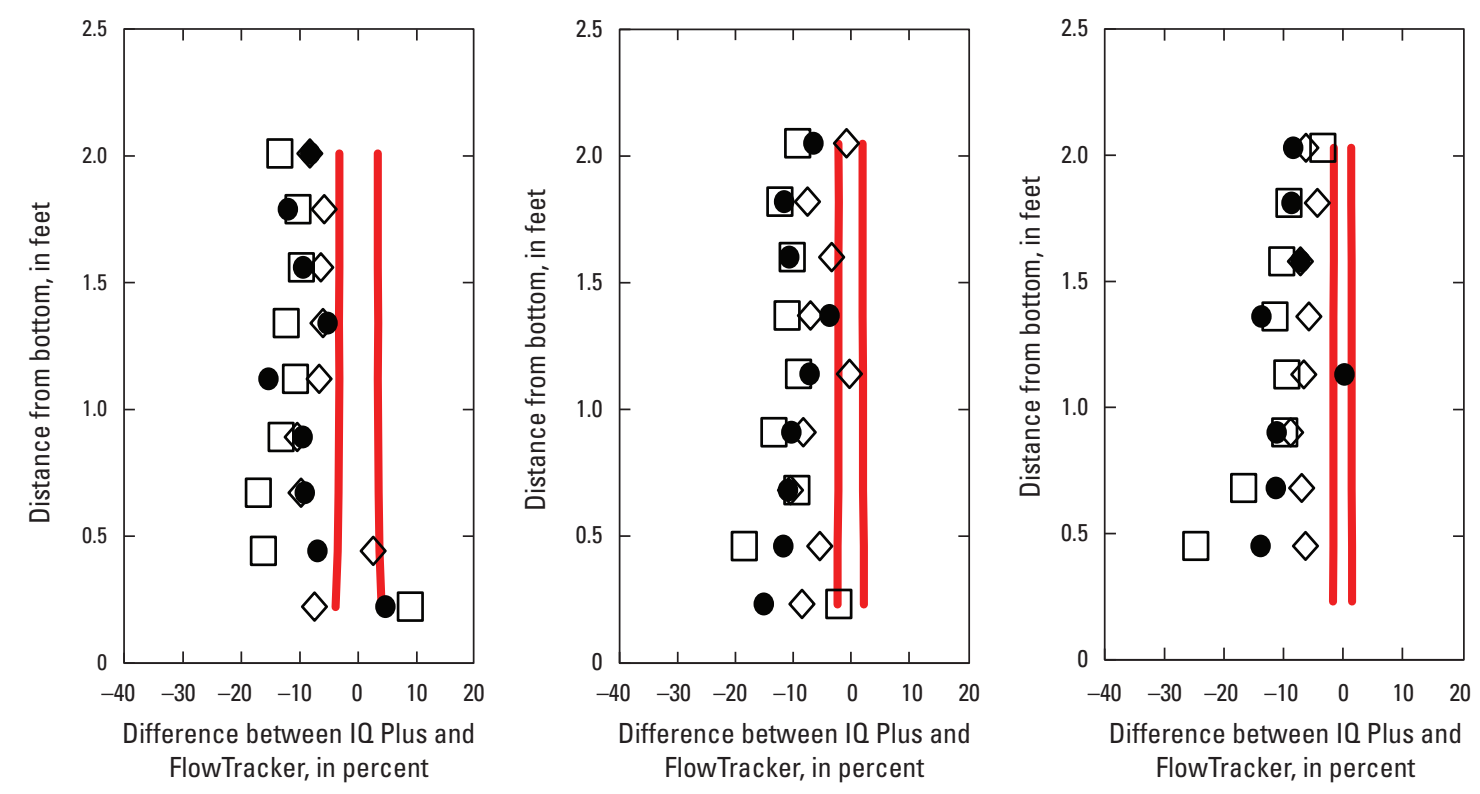

EXPLANATION

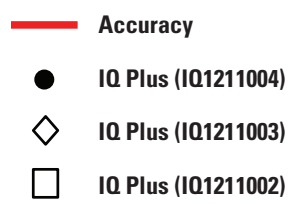

Figure 12. Percent velocity difference between the SonTek-IQ Plus using firmware 1.52 and the FlowTracker for velocity profiles measured for average stream-wise velocities of $0.7,1.4$, and 3.2 feet per second (as measured by the FlowTracker) plotted with the IO Plus accuracy (red lines). 
Table 3 lists the mean-profile velocity measured by each IQ Plus and the FlowTracker, along with the computed percent mean-velocity difference. The mean-profile velocity at a discharge was computed by averaging all the individual cell velocities over the flow depth. Figure 13 is a plot of percent difference between IQ Plus and FlowTracker mean-profile velocities over the range of mean-flume velocities tested. The

Table 3. Mean-profile velocity measured with SonTek-IO Plus using firmware 1.52 and with FlowTracker. Percent differences are computed as $100 \times$ (IO Plus - FlowTracker)/FlowTracker.

[ft/s, feet per second]

\begin{tabular}{|c|c|c|c|}
\hline \multicolumn{2}{|c|}{ IO Plus } & \multirow{2}{*}{$\begin{array}{l}\text { FlowTracker } \\
\text { Mean velocity, } \\
\text { in } \mathrm{ft} / \mathrm{s}\end{array}$} & \multirow{2}{*}{$\begin{array}{l}\text { Percent } \\
\text { difference }\end{array}$} \\
\hline Serial number & $\begin{array}{l}\text { Mean velocity, } \\
\text { in } \mathrm{ft} / \mathrm{s}\end{array}$ & & \\
\hline \multirow[t]{3}{*}{ IQ11151134 } & 0.560 & 0.635 & -11.8 \\
\hline & 1.01 & 1.13 & -10.5 \\
\hline & 1.76 & 1.99 & -10.8 \\
\hline \multirow[t]{3}{*}{ IQ1211002 } & 0.612 & 0.686 & -10.9 \\
\hline & 1.28 & 1.43 & -10.3 \\
\hline & 2.98 & 3.32 & -11.8 \\
\hline \multirow[t]{3}{*}{ IQ1211003 } & 0.631 & 0.676 & -6.57 \\
\hline & 1.36 & 1.44 & -5.53 \\
\hline & 2.97 & 3.14 & -5.41 \\
\hline \multirow[t]{3}{*}{ IQ1211004 } & 0.625 & 0.681 & -8.23 \\
\hline & 1.30 & 1.43 & -9.52 \\
\hline & 2.92 & 3.15 & -7.50 \\
\hline
\end{tabular}

manufacturer's and Price Type AA USGS accuracy criteria (Hubbard and others, 1999) are also plotted in figure 13. The difference was computed as $100 \mathrm{x}$ (IQ Plus - FlowTracker)/ FlowTracker. The differences are between -5 and -12 percent and vary more by sn than by velocity.

The IQ Plus differences are larger than those found by a test of a standard IQ by the Bureau of Reclamation (BOR) (Heiner and Vermeyen, 2012). The BOR test had positive bias for mean velocities less than $1 \mathrm{ft} / \mathrm{s}$ and negative bias for mean velocities greater than $1 \mathrm{ft} / \mathrm{s}$. The bias for the BOR test was 12.9 percent at a mean velocity of $0.56 \mathrm{ft} / \mathrm{s},-1.2$ percent at $1.12 \mathrm{ft} / \mathrm{s}$, and -6.1 percent at $1.52 \mathrm{ft} / \mathrm{s}$. The BOR test was in a slightly smaller flume ( $4 \mathrm{ft}$ wide instead of $5 \mathrm{ft}$ ), tested only one IQ instrument, and had a larger range of flow depths over similar mean velocities-2.24, 3.34, and $4.11 \mathrm{ft}$-in comparison to depths of 2.24, 2.28, and $2.26 \mathrm{ft}$. The IQ is similar to the IQ Plus, except it does not measure velocity profiles, lacks the capability to compute discharges in a "natural" channel section, and can be used only in water depths up to $5 \mathrm{ft}$.

\section{Discharge and Velocity Measurements with Firmware 1.60}

Discharge measurement comparisons are shown in table 4 for the three instruments tested side by side (sns IQ1211002, IQ1211003, and IQ1211004) using firmware 1.60 and SonTek's "theoretical" discharge method. As in the previous test, the FlowTracker was used as the reference measurement and the uncertainty of the reference measurement was estimated as 1.9 percent. The percent differences shown in table 4 were

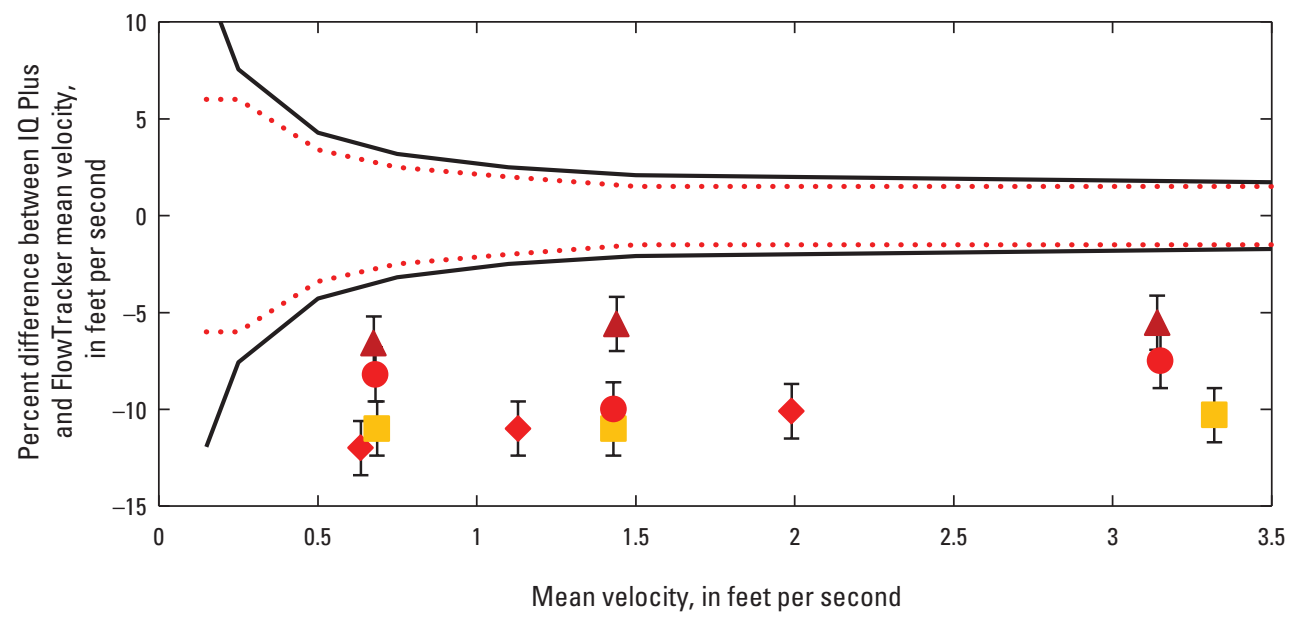

EXPLANATION

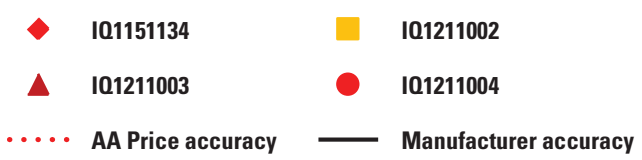

Figure 13. Percent difference between SonTek-IO Plus using firmware 1.52 and FlowTracker mean-profile velocity at various mean-flow velocities from 0.5 to about 3.25 feet per second. Vertical error bars represent the uncertainty of the FlowTracker velocity. 
computed as for table 2 . The discharge bias was much smaller than the previous test and ranged from -1.6 to -7.3 percent and averaged -4.8 percent for the test discharges. For the two lowest test velocities, the IQ Plus measured in 30 to 33 cells. At the highest test velocity, the IQ Plus usually measured using 9 cells and pulse-incoherent-type pings, but periodically switched to 30 cells and pulse-coherent-type pings. All results at the highest test discharge are for data with nine cells. There is not an obvious trend to the differences with increasing discharge (fig. 14). Figure 14 shows plots of percent difference

Table 4. Mean-profile velocity measured with SonTek-I0 Plus using firmware 1.60 and with FlowTracker. Percent differences are computed as 100 x (IO Plus - FlowTracker)/FlowTracker.

$\left[\mathrm{ft}^{3} / \mathrm{s}\right.$, cubic feet per second]

\begin{tabular}{|c|c|c|c|}
\hline \multicolumn{2}{|c|}{ SonTek-I0 Plus } & \multirow{2}{*}{$\begin{array}{c}\text { FlowTracker } \\
\text { Discharge, } \\
\text { in } \mathrm{ft}^{3} / \mathrm{s}\end{array}$} & \multirow{2}{*}{$\begin{array}{c}\text { Percent } \\
\text { difference }\end{array}$} \\
\hline Serial number & $\begin{array}{c}\text { Discharge, } \\
\text { in } \mathrm{ft}^{3} / \mathrm{s}\end{array}$ & & \\
\hline \multirow[t]{3}{*}{ IQ1211002 } & 7.85 & 8.00 & -1.86 \\
\hline & 19.27 & 19.58 & -1.58 \\
\hline & 35.52 & 36.11 & -1.61 \\
\hline \multirow[t]{3}{*}{ IQ1211003 } & 7.74 & 8.00 & -3.29 \\
\hline & 18.49 & 19.58 & -5.56 \\
\hline & 33.52 & 36.11 & -7.17 \\
\hline \multirow[t]{3}{*}{ IQ1211004 } & 7.37 & 8.00 & -7.88 \\
\hline & 18.3 & 19.58 & -6.54 \\
\hline & 33.47 & 36.11 & -7.29 \\
\hline
\end{tabular}

between the IQ Plus and FlowTracker discharges, with vertical error bars of \pm 1.9 percent, the estimated uncertainty of the FlowTracker discharge measurement. The plot also includes the USGS subjective discharge rating criteria. All measured discharges by sn IQ1211002 using firmware 1.60 were rated excellent. All other discharge measurements were rated as either good (1) or fair (4). In contrast with the earlier test, none were rated as poor. It was anticipated that the IQ Plus "theoretical" discharge measurements would all be excellent in the controlled flow and channel conditions in the laboratory flume. However, only one IQ Plus of the three tested with firmware 1.60 measured discharges consistently within the manufacturer's suggested accuracy of 3 to 5 percent (Xylem, 2012, p. 97). Based on the three instruments tested, the IQ Plus "theoretical" discharge measurements with firmware 1.60 usually do not meet the manufacturer's suggested discharge accuracy. Because the "theoretical" method used by the IQ Plus is not documented, the USGS does not recommend its use.

The velocity profiles measured by the IQ Plus instruments and the FlowTracker are shown in figure 15. As with the previous test, the center-cell velocity measurements of the IQ Plus instruments are plotted in figure 15 with the nearest FlowTracker measurements. The IQ Plus profile measurements (fig. 15) either straddle the FlowTracker profile measurements or slightly underregister the profile velocities.

The percent velocity differences between the velocity measured by the IQ Plus and the FlowTracker are plotted in figure 16 with the IQ Plus accuracy specification. The percent velocity differences were computed as $100 \mathrm{x}$ (IQ Plus - FlowTracker)/FlowTracker). The error bars represent the accuracy of the reference velocity measurement

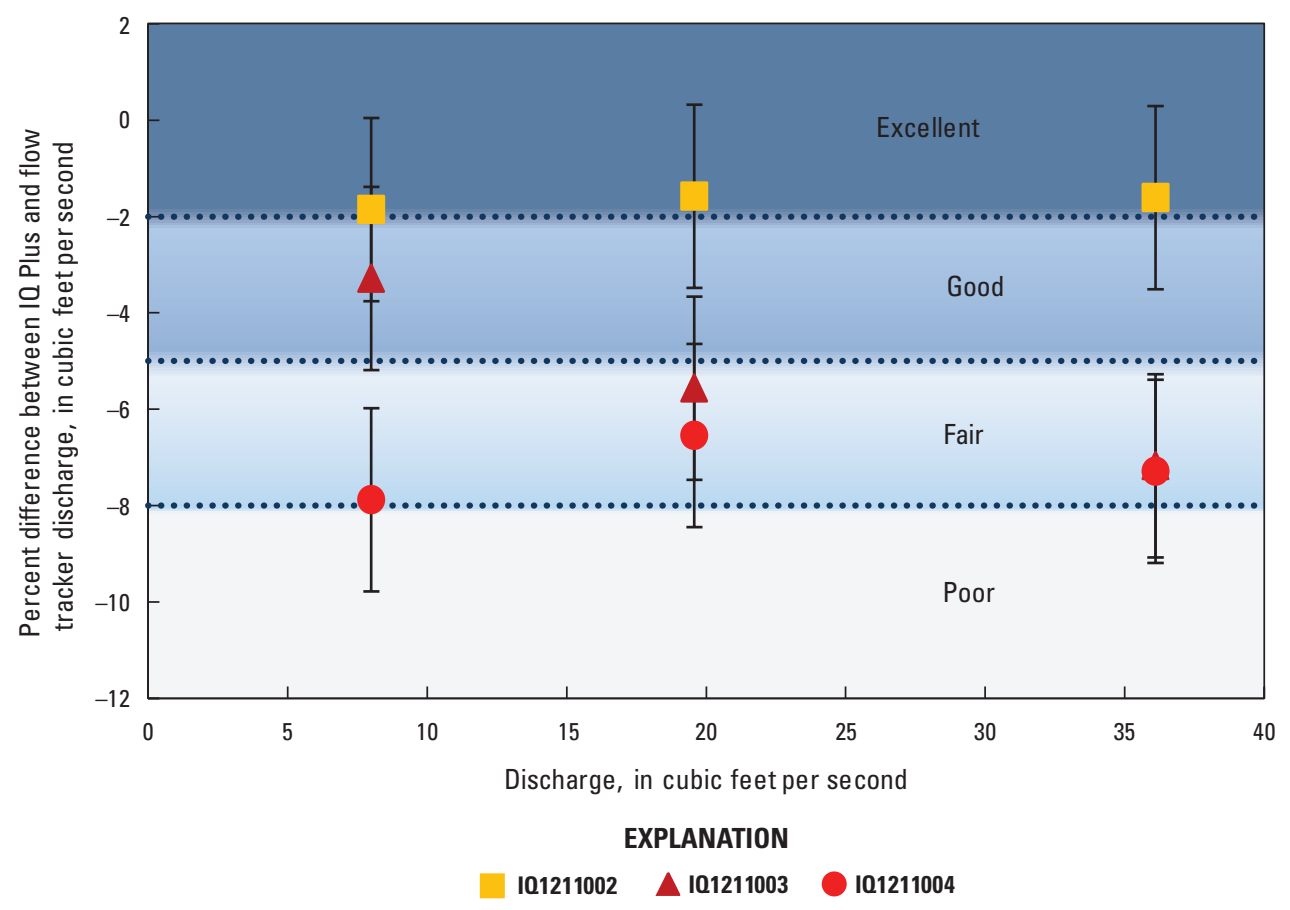

Figure 14. Percent difference in discharge between SonTek-IO Plus using firmware 1.60 and SonTek's "theoretical" computation method and FlowTracker using midsection method for discharges from approximately 7 to 36 cubic feet per second. 

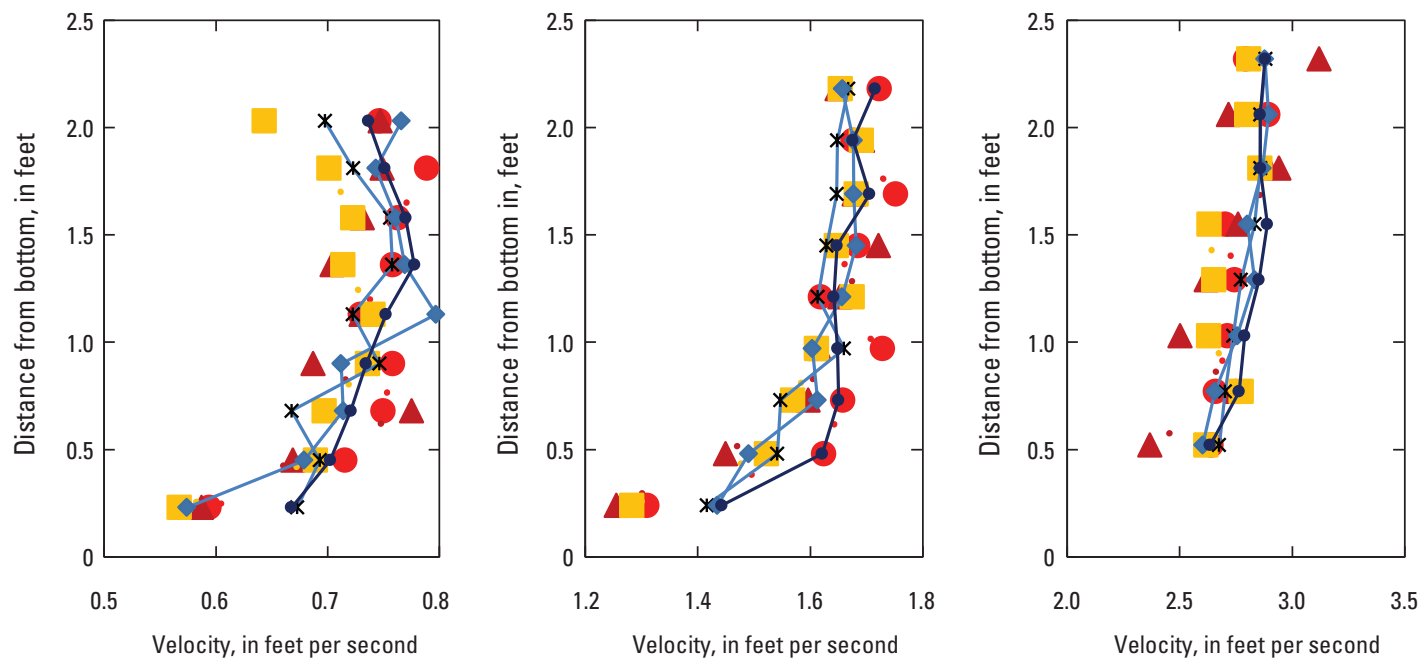

EXPLANATION

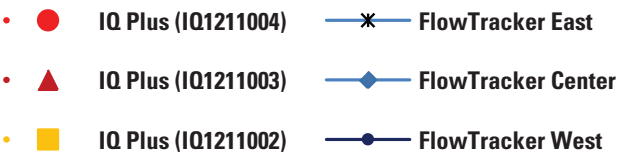

Figure 15. Velocity profiles measured by SonTek-IO Plus using firmware 1.60 and FlowTracker for average stream-wise velocities of $0.7,1.6$, and 2.7 feet per second (as measured by the FlowTracker).
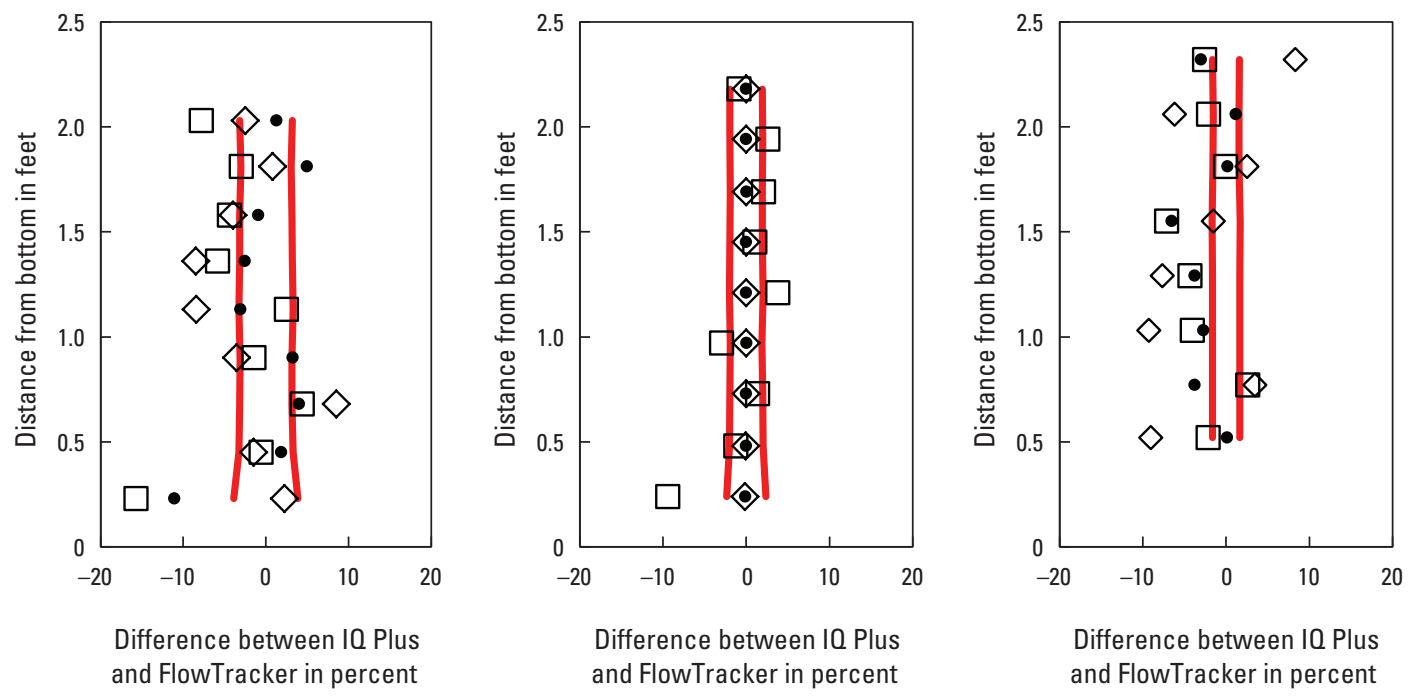

\section{EXPLANATION}

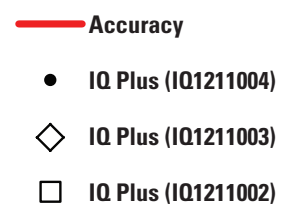

Figure 16. Percent velocity difference between the SonTek-I0 Plus using firmware 1.60 and the FlowTracker for velocity profiles measured for average stream-wise velocities of $0.7,1.6$, and 2.7 feet per second (as measured by the FlowTracker) plotted with the IO Plus accuracy (red lines). 
(FlowTracker). For a mean velocity of $1.4 \mathrm{ft} / \mathrm{s}$, the IQ Plus cell velocities are generally within the manufacturer's accuracy specification. For the other two mean velocities, 0.7 and $3.2 \mathrm{ft} / \mathrm{s}$, the velocities are usually within \pm 10 percent of the FlowTracker measurements.

Table 5 lists the mean-profile velocity measured by each IQ Plus and the FlowTracker, along with the computed percent mean-velocity difference. As in the previous test, the meanprofile velocity at a flume discharge was computed by averaging over depth all the individual profile velocities at a flume

Table 5. Mean-profile velocity measured with SonTek-I0 Plus using firmware 1.60 and with FlowTracker. Percent differences are computed as 100 x (IO Plus - FlowTracker)/FlowTracker.

$[\mathrm{ft} / \mathrm{s}$, feet per second]

\begin{tabular}{|c|c|c|c|}
\hline \multicolumn{2}{|c|}{ SonTek-IO Plus } & \multirow{2}{*}{$\begin{array}{l}\text { FlowTracker } \\
\text { Mean velocity, } \\
\text { in } \mathrm{ft} / \mathrm{s}\end{array}$} & \multirow{2}{*}{$\begin{array}{c}\text { Percent } \\
\text { difference }\end{array}$} \\
\hline Serial number & $\begin{array}{l}\text { Mean velocity, } \\
\text { in } \mathrm{ft} / \mathrm{s}\end{array}$ & & \\
\hline \multirow[t]{3}{*}{ IQ1211002 } & 0.690 & 0.715 & -3.50 \\
\hline & 1.592 & 1.597 & -0.26 \\
\hline & 2.721 & 2.79 & -2.48 \\
\hline \multirow[t]{3}{*}{ IQ1211003 } & 0.709 & 0.724 & -2.09 \\
\hline & 1.59 & 1.61 & -1.24 \\
\hline & 2.722 & 2.786 & -2.31 \\
\hline \multirow[t]{3}{*}{ IQ1211004 } & 0.734 & 0.735 & -0.15 \\
\hline & 1.641 & 1.638 & 0.17 \\
\hline & 2.751 & 2.815 & -2.29 \\
\hline
\end{tabular}

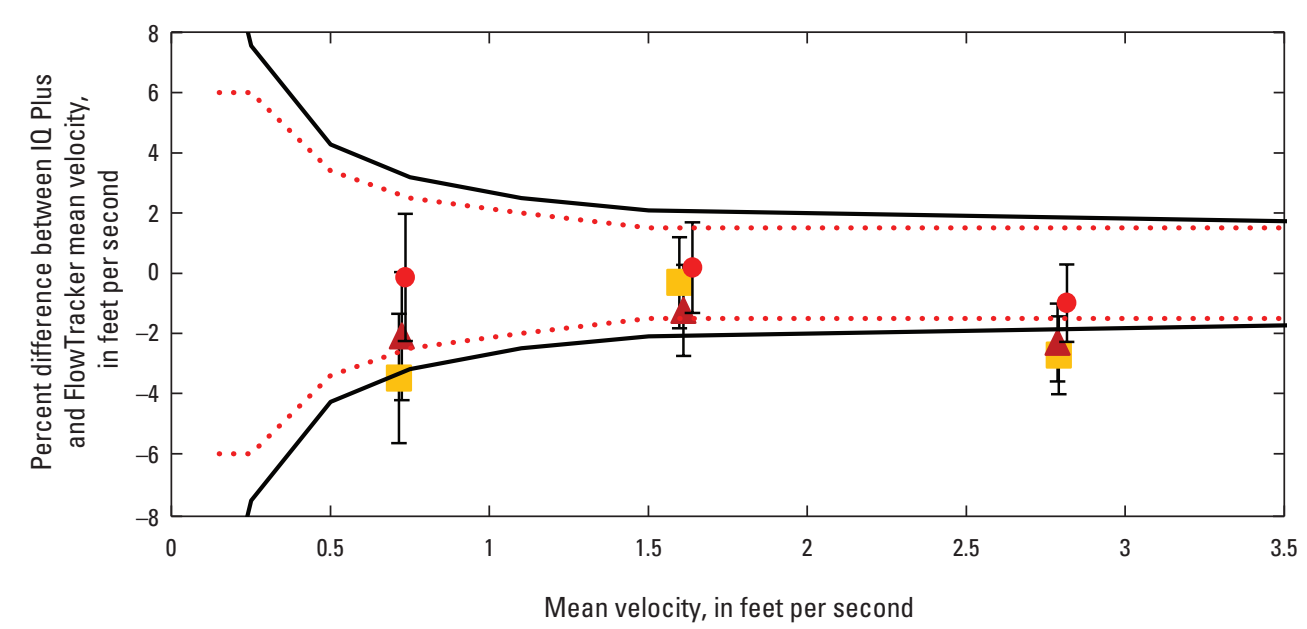

EXPLANATION

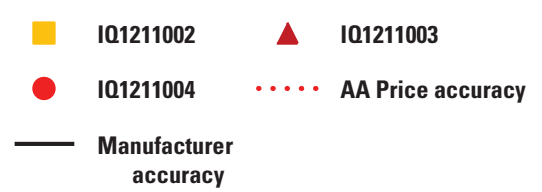

Figure 17. Percent difference between SonTek-IQ Plus using firmware 1.60 and FlowTracker mean-profile velocity at various mean-flow velocities from 0.7 to about 2.7 feet per second (ft/s). Vertical error bars represent the uncertainty of the FlowTracker velocity. discharge. Figure 17 is a plot of percent difference between IQ Plus and FlowTracker mean-profile velocities over the range of mean-flume velocities tested. The percent difference was computed as $100 \mathrm{x}$ (IQ Plus - FlowTracker)/FlowTracker. The manufacturer's and Price Type AA USGS accuracy criteria are also plotted in figure 17. For the flume velocities tested, the differences are between -2.50 and 0.17 percent. When the uncertainty (or accuracy) of the FlowTracker is included, all the mean velocities measured by the IQ Plus instruments are within the accuracy criteria of a Price Type AA meter and the manufacturer's accuracy specification. Therefore, the IQ Plus with firmware 1.60 is considered to be an acceptable index velocity instrument for the USGS. Percent differences are computed as $100 \mathrm{x}$ (IQ Plus - FlowTracker)/FlowTracker.

\section{SDI-12 compliance}

All four IQ Pluses were tested for SDI-12 compliance using the NR Systems SDI-12 verifier. Once all four IQ Pluses had their output type in the Real Time Data menu changed to SDI-12 output, they all passed the verifier test. The output must be changed to SDI-12 output or the IQ Plus will not function properly as an SDI-12 device.

\section{Operating Observations}

The IQ Plus software (fig. 18) was easy to use and made quick work of setting up the IQ Plus in the flume for testing.

The software gave warnings during stage testing when the instrument was tilted beyond the 5 degrees it needs to measure stage accurately (fig. 19). The software has many options for viewing and exporting the data. After collecting test data, it was relatively easy to export the data into tables for comparisons with the FlowTracker data.

The instrument has a very low profile compared to the previous SonTek SW sensor and was easy to install for testing in the flume. Some provision will have to be made at field sites to protect the communication/power cable assembly. The manual gives good guidance on installing the IQ Plus and protecting the cable assembly. The manual is well written and easy to follow. 


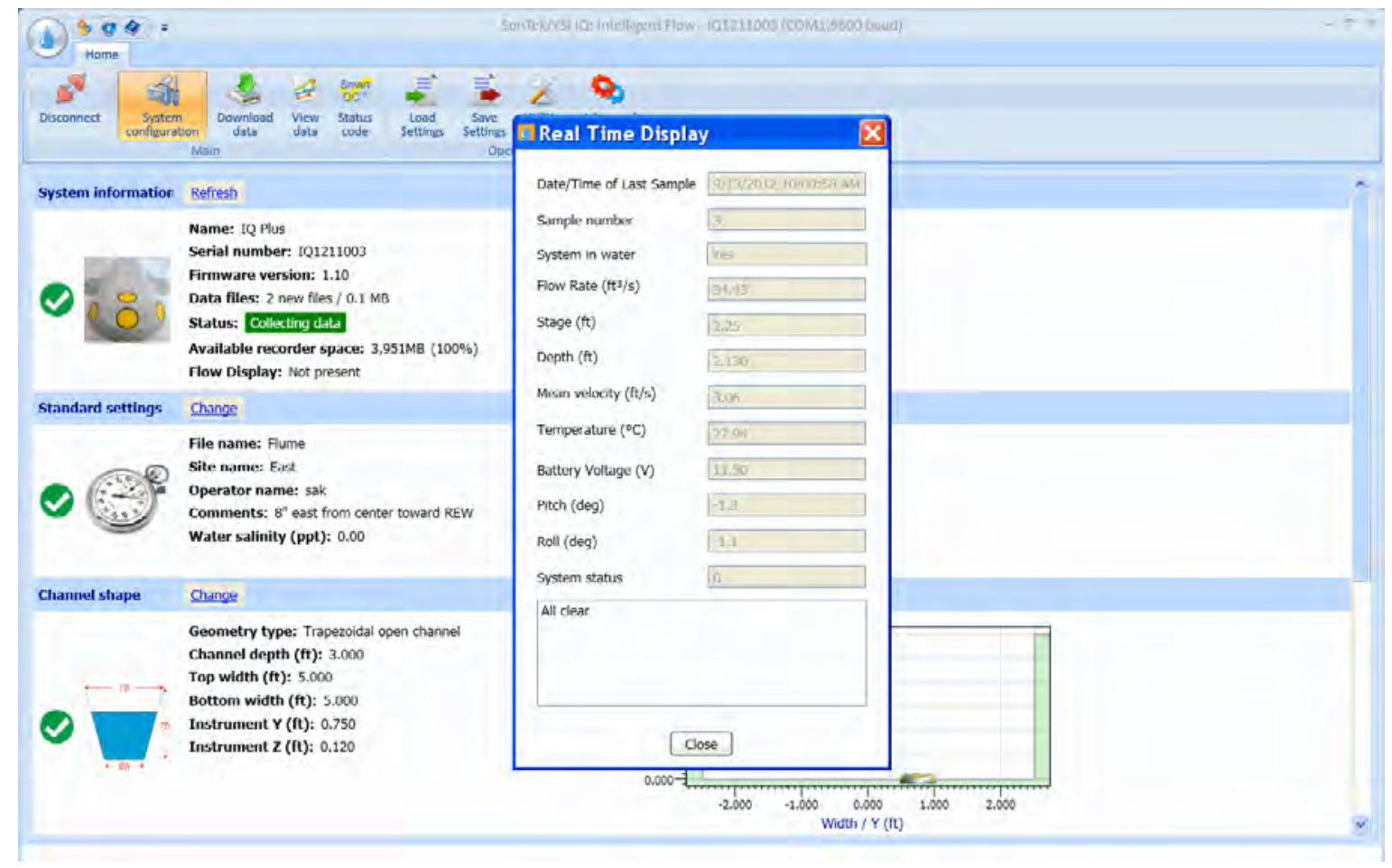

Figure 18. Screen shot of SonTek-IQ Plus software showing the setup menu.

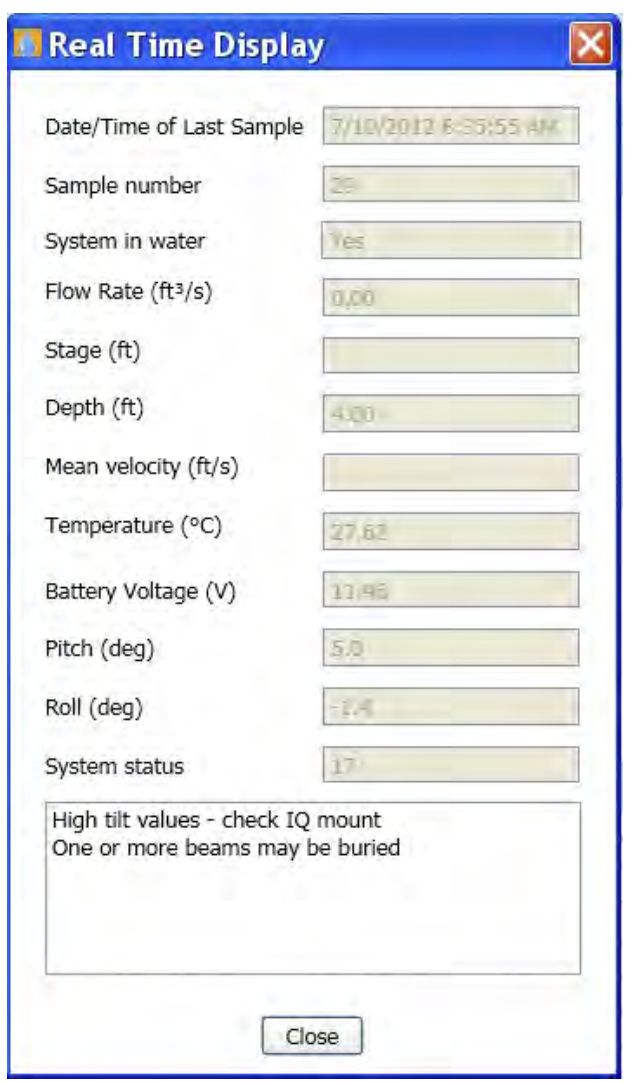

Figure 19. Screen shot of tilt warning given when SonTek-IO Plus is installed with a tilt greater than 5 degrees.

\section{Summary}

Evaluation testing of the SonTek-IQ Plus (IQ Plus) was performed to assess the accuracy of the instrument's water depth, discharge, and velocity measurements. Four IQ Plus instruments were tested using firmware versions 1.52 and 1.60, a loaner instrument, and three purchased instruments. The water-depth accuracy test was performed in the jet tank at the USGS HIF Hydraulics Laboratory to test the effect of pitch-and-roll angles on the depth measurement. Discharge and velocity accuracy tests were performed in a large indoor tilting flume in a 5 -ft-wide, approximately 2.3 -ft-deep section with mean velocities of $0.5,1,2$, and $3 \mathrm{ft}$ per second at the USGS Hydraulics Laboratory at the HIF.

The IQ Plus readings were within the $\pm 0.01 \mathrm{ft}$ of the laboratory depth reference for pitch-and-roll angles of 0 degrees in water depths up to $7 \mathrm{ft}$. The IQ Plus depth measurements met the USGS requirements and the manufacturer's accuracy specification when the unit was installed, according to the manufacturer's instructions with less than 5 degrees pitch and roll. However, because of the limited depth testing conducted, the IQ Plus depth measurement is not recommended as a primary stage measurement.

The differences between the IQ Plus "theoretical" discharge and the FlowTracker measured discharge ranged from -2.4 to -11.6 percent for instruments using firmware 1.52. Instruments using firmware $1.60 \mathrm{had}$ no discharge measurements that differed by more than 7.50 percent from the FlowTracker measurements. One instrument using firmware 1.60 had all discharge measurements within 2 percent 
of the FlowTracker measurements. The differences with the FlowTracker measured discharges ranged from -1.6 to -7.9 percent. It was anticipated that the IQ Plus "theoretical" discharge measurements would all be excellent in the controlled flow and channel conditions in the laboratory flume. The 1.60 firmware performed better than the 1.52 firmware. However, the IQ Plus discharges measured using SonTek's "theoretical" method usually did not meet the manufacturer's suggested discharge accuracy of 3 to 5 percent when compared with FlowTracker discharge measurements using the midsection method. The discharge computed by the SonTek-IQ Plus using the "theoretical" method is not expected to be as accurate as a discharge computed with the USGS-recommended index velocity method.

For both firmware versions, differences with the FlowTracker velocity measurements tended to be negative. Velocities measured using firmware 1.52 had a general negative bias and frequently did not meet the manufacturer's accuracy specification for the IQ Plus. Mean-profile velocity differences ranged from -6 to -12 percent when compared to FlowTracker mean-profile velocity. Velocities measured using firmware 1.60 had a smaller negative bias than the velocities measured with firmware 1.52 . Mean-profile velocity differences using firmware 1.60 ranged from -2.50 to 0.17 percent when compared to the FlowTracker. Mean-profile velocity measurements with firmware 1.52 did not meet either the manufacturer's specifications or Price Type AA meter accuracy requirements when compared with FlowTracker measurements. Mean-velocity measurements with firmware $1.60 \mathrm{met}$ the manufacturer's specification and Price Type AA meter accuracy requirements when compared with FlowTracker measurements. The IQ Plus with firmware 1.60 is considered acceptable for use as an index velocity instrument for the USGS.

\section{References Cited}

Cook, Mike, Bird, Steven, and Corbett, Arran, 2012, Using the SonTek IQ Plus to measure flow in open irrigation channels-A case study on flow meter accuracy and resource management: Irrigation Australia 2012 Conference, 63d International Executive Council and 7th Asian Regional Conference Proceedings, June 24-30, 2012. (Also available at http://irrigation.org.au/documents/publicationsresources/conference_papers_2012/Using_the_SonTek_IQ Plus_to_measure_flow_in_open_irrigation_channels.pdf.)

Heiner, B.J., and Vermeyen, T.B., 2012, Laboratory evaluation of open channel area-velocity flow meters: Bureau of Reclamation Hydraulic Laboratory Report HL-2012-03, 15 p.

Hubbard, E.F., Thibodeaux, K.G., and Duong, M.N., 1999, Quality assurance of U.S. Geological Survey stream current meters; The meter exchange program 1988-98: U.S. Geological Survey Open-File Report 99-221, 15 p.
International Organization for Standardization, (1993)

Guide to the expression of uncertainty in measurement, ISBN 92-67-10188-9, ISO: Geneva, Switzerland.

Levesque, V.A., and Oberg, K.A., 2012, Computing discharge using the index velocity method: U.S. Geological Survey Techniques and Methods 3-A23, 148 p. (Also available at http://pubs.usgs.gov/tm/3a23/.)

Mitutoyo Inc., 2003, Pro 360 manual, accessed Feb 5, 2014, at http://ecatalog.mitutoyo.com/Manuals.aspx?c=1438.)

Mueller, D.S., Wagner, C.R., Rehmel, M.S., Oberg, K.A,, and Rainville, Francois, 2013, Measuring discharge with acoustic Doppler current profilers from a moving boat (ver. 2.0, December 2013): U.S. Geological Survey Techniques and Methods, book 3, chap. A22, 95 p., at http://dx.doi.org/10.3133/ tm3A22.

Nolan, K.M., and Shields, R.R., 2000, Measurement of stream discharge by wading: U.S. Geological Survey WaterResources Investigations Report 00-4036, 34 p.

SDI-12 Support Group, 2013, SDI-12-A serial-digital interface standard for microprocessor-based sensors, version 1.3, 27 p., at http://www.sdi-12.org/current $\% 20$ specification/ SDI-12_version1_3\%20January\%2026,\%202013.pdf.

SonTek/YSI Inc., July 2007, FlowTracker handheld ADV user's manual: San Diego, Calif., SonTek/YSI Inc., at http://www.sontek.com.

SonTek/YSI Inc., 2011, White Paper-Product Introduction; The SonTek-IQ: San Diego, Calif., SonTek/YSI Inc., at http://ysi. actonsoftware.com/acton/attachment/1253/f-0035/1/-/-///-/ SonTek-IQ\%20Overview\%20and\%20Application.pdf.

Turnipseed, D.P., and Sauer, V.B., 2010, Discharge measurements at gaging stations: U.S. Geological Survey Techniques and Methods book 3, chap. A8, p. 2-8. (Also available at http://pubs.usgs.gov/tm/tm3-a8/.)

Xylem Incorporated, 2012, SonTek IQ intelligent flow user's manual: San Diego, Calif., Xylem Incorporated, at http:// www.sontek.com.

U.S. Geological Survey, 1996, Policy concerning accuracy of stage data: U.S. Geological Survey, Office of Surface Water Technical Memorandum 96.05. 



\section{$\frac{1}{8}$}

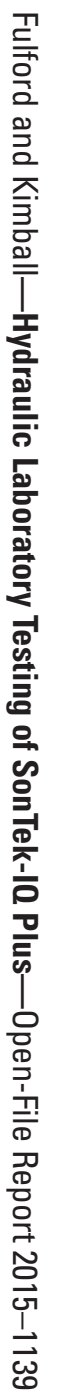

